\title{
4 The success view I - Agentive abilities
}

So far, this book has been rather destructive. Let us now switch into construction mode. In this and the next chapter, I will take all of the insights from the last two chapters and use them to come up with a new, and, as I will argue, superior view of abilities: the success view of ability. I will proceed in two steps. In this chapter, I'll be dealing exclusively with agentive abilities and developing the success view for abilities of that kind. In the next chapter, the view is going to be extended to cover non-agentive abilities as well. By the end of the next chapter, we'll have arrived at a fully general and comprehensive view of abilities - the success view of abilities tout court.

Why start with agentive abilities? For three simple reasons. First, the paradigmatic cases of abilities are of the agentive kind. When asked to name a few abilities, most people come up with abilities to play instruments, do some sport or other, drive a car, cook a dish, play a game, and so on. This is no coincidence. A brief look into the Corpus of Contemporary American English (COCA) makes it evident that ascriptions of agentive abilities are by far the most prevalent ones. I take it to be reasonable to start an investigation of the subject matter from there.

Secondly, the success view of agentive abilities will turn out to be rather concrete where the success view of abilities tout court will necessarily have to remain somewhat abstract. In the following sense: abilities tout court, I will argue, are a matter of success; and success, in turn, I will argue, is a matter of a certain modal tie between certain triggers and responses. The good thing about agentive abilities is that we can actually specify what the crucial trigger is in such cases; namely an intention to $\phi$ (or, on a weaker reading, some other properly related intention). When it comes to the success view of abilities tout court, all we can say is that the trigger will have to be such that $\phi$-ing in response to it counts as a success. I therefore take it to be helpful to have worked out the success view of agentive abilities before moving on to the more abstract formulation of the view. (If this sounds somewhat obscure to you at this point, fear not. All of this is going to be developed very systematically in this and the next chapter.)

Thirdly, and relatedly, the success view of agentive abilities can in large parts avail itself of descriptive terms where the success view of abilities tout court employs normative terminology. In the typical cases, to have an agentive ability is for a certain modal tie between the intention to $\phi$ and performances of $\phi$-ing to obtain; no normative vocabulary here. For an agent to have an ability tout court is for there to be a certain modal tie between a certain trigger and the agent's $\phi$ ing, where the trigger is specified as one in response to which $\phi$-ing counts as a

2 OpenAccess. (c) 2020 Jaster, published by De Gruyter. (cc) BY-NC-ND This work is licensed under the Creative Commons Attribution-NonCommercial-NoDerivatives 4.0 License. 
success. What counts as a success obviously has a normative dimension to it. Not that there is anything wrong with this normative component. In fact, I take it to be clear that abilities have some normative dimension to them. Yet, it is not particularly easy to pinpoint where exactly the normativity stems from. It is therefore somewhat comforting that the more specific version of the view - the success view of agentive abilities - can in large parts do away with normative notions.

All this being said, let's forget about non-agentive abilities for the time being, and concentrate on the paradigmatic instances of abilities: abilities to perform actions. Let us focus on abilities like the ability to sing, to dance, or to jump; to eat, to cook, or to pour water; to sketch a tree, to chase a cat, or to hole a putt; and so on. Let's focus exclusively on agentive abilities and forget about the rest.

Here is a road map for the chapter. In the next section, 4.1, I will introduce the basic framework of the success view of agentive abilities in quite some detail. As I go along, it will become evident that the success view incorporates key insights both of the simple conditional analysis and possibilism. That is because the success view of agentive abilities incorporates both the idea that abilities have something to do with a modal tie between intentions and performances and the idea that abilities are always had in view of contextually variant sets of facts. In a way, then, the success view of agentive abilities can be seen as a hybrid view of the simple conditional analysis and possibilism. I view this as a merit. I take it to be highly likely that other philosophers were not completely off course in their assessment of the topic.

In section 4.2, I am going to talk in some detail about the notion of an intention as it figures in the formulation of the view and provide a rationale for formulating the success view in terms of intentions and not some other candidate motivational state on the agent's part.

In sections 4.3-4.7, I show that the success view of agentive abilities is superior to both the simple conditional analysis and possibilism in that it accounts for all of the adequacy conditions (apart from accounting for non-agentive abilities, of course) and does not run into any of the problems that beset the other two views.

More specifically, I will argue that the success view provides an account of degrees and the corresponding kind of context sensitivity that attaches to ability statements $(\rightarrow 4.3)$, circumvents the problem of the impeded intention $(\rightarrow 4.4)$, provides a fully comprehensive account of general and specific abilities $(\rightarrow$ 4.5), yields an understanding of the workings of masks ( $\rightarrow 4.6)$, and does not only avoid the formal problem that besets possibilism, but actually explains where that problem stems from $(\rightarrow 4.7)$. In view of those merits, I will conclude, 
by the end of the section 4.7, that the success view is a very promising view indeed.

Sections 4.8 and 4.9, finally, are devoted to the discussion of two objections to the success view that come to mind quite naturally. In section 4.8, I'll discuss the objection that the success view runs into problems with what I will call "unintentional agentive abilities" - agentive abilities which can only be exercised as long as the agent does not intend to exercise them.

In section 4.9, the worry is refined by examining a specific kind of unintentional agentive abilities: abilities that can only be exercised as long as the agent does not intend to exercise them, because the agent is epistemically impaired in certain ways. In response to these worries, I will introduce a somewhat weaker version of the success view, which accommodates such cases. By the end of the chapter $(\rightarrow 4.10)$, we'll be in a position to formulate a fully comprehensive account of agentive abilities.

I would like to emphasize beforehand that I am hugely indebted to Manley and Wasserman's work on dispositions. The idea that abilities have something to do with proportions is greatly inspired by their work. On their view, $\mathrm{x}$ has a disposition to $\mathrm{M}$, "if and only if $\mathrm{x}$ would $\mathrm{M}$ in some suitable proportion of [stimulus cases]" (Manley \& Wasserman 2008: 76, my emphasis). Although Manley and Wasserman's account of dispositions differs from my views on abilities in some crucial respects (their view is a more sophisticated version of the conditional analysis of dispositions and is going to be discussed in detail in chapter 6.2), I nevertheless view it as a very close relative to the success view of ability in that it emphasizes the notion of a proportion - a feature that can be found in a variety of views, all of which are going to be discussed in chapter 6 .

\subsection{The general framework}

On the view I want to develop and defend in this chapter, having an agentive ability is a matter of modal success. More specifically, I will argue that for an agent to have an agentive ability to $\phi$, that agent's intentions to $\phi$ and her performances of $\phi$-ing have to match up in the right way across a certain portion of modal space. Agentive abilities are a matter of a specific modal tie between intentions and performances on this account.

As you will note, this idea pays tribute to the intuition that also drives the simple conditional analysis of abilities. According to the simple conditional analysis, an agent has an ability if and only if the agent would $\phi$ if she intended to $\phi$. Thus, the simple conditional analysis, too, postulates a specific modal tie between the agent's intentions and her performances. But as we have seen in 
chapter 2, that tie is not plausibly construed in terms of a counterfactual conditional.

What is the modal tie that matters, then? Here is my suggestion. According to what I will call the success view of agentive abilities, or simply $\mathrm{SUCCESS}_{\mathrm{AA}}$, in what follows,

SUCCESS $_{\mathrm{AA}}$. an agent $\mathrm{S}$ has an agentive ability to $\phi$ if and only if $S \phi$ 's in a sufficiently high proportion of the relevant possible situations in which she intends to $\phi$.

Thus, a darts player has the ability to hit the bull's eye if and only if she hits it in a sufficiently high proportion of relevant possible situations in which she intends to hit it. An engineer has the ability to construct a super-efficient engine if and only if she succeeds in constructing one in a sufficiently high proportion of relevant possible situations in which she intends to construct one. And a pianist has the ability to play a certain piece if and only if she succeeds in playing it in a sufficiently high proportion of relevant possible situations in which she intends to play it.

In fact, this is a simplification. As we will see later on, SUCCESS $\mathrm{AA}_{\mathrm{A}}$ is only approximately correct. Really, the proportion that matters will have to be weighted $(\rightarrow 4.3)$ and the agent's intention does not necessarily have to be the intention to $\phi$, but may well be some other intention, in response to which $\phi$-ing counts as a success $(\rightarrow 4.8)$. But those complications need not bother us right now. SUC$\mathrm{CESS}_{\mathrm{AA}}$ is close enough to what I take to be the truth to get along with it throughout the largest part of the chapter. The full-fledged version of the success view of agentive abilities, which does justice to the full amount of complexity of its subject matter, is going to emerge as we go along and can be found in the upshot in section 4.10. For now, let's keep things as simple as possible.

What is a proportion? A proportion, as I am using the term, is simply a portion or part in its relation to the whole. ${ }^{1}$ The proportion of blondes among the Swedes, for instance, is the portion of blonde Swedes in relation to all Swedes. Mathematically, a proportion corresponds to a certain ratio. To use our example again, the proportion of blondes among the Swedes corresponds to the ratio of blonde Swedes to the totality of Swedes. It can be expressed by a fraction. The ratio of blonde Swedes to all Swedes is $\mathrm{v}$, such that $\mathrm{v}=$ size of the set of blonde Swedes/size of the set of all Swedes.

1 I follow the Oxford dictionary here, which defines "proportion" as "a portion or part in its relation to the whole; a comparative part, a share; sometimes simply, a portion, division, part" (Simpson \& Weiner 1989). 
The same goes for the proportion of performance cases among the relevant

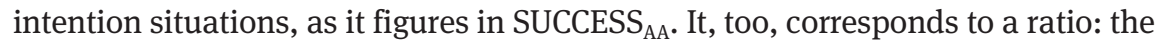
ratio of relevant intention situations in which the agent $\phi$ 's to the totality of all relevant intention situations. Again, this can be expressed by a fraction. The ratio that matters is $\mathrm{v}$, such that $\mathrm{v}=$ size of the set of relevant intention situations in which the agent $\phi$ 's/size of the set of the all relevant intention situations. We can call this ratio the agent's modal success rate. Hence, SUCCESS AA $_{\text {states that }}$ an agent has the ability to $\phi$ if and only if her modal success rate is high enough.

It is important to note that the modal success rate is not to be conflated with the agent's quota of successful attempts in the actual world. Let's distinguish the two ratios very carefully. The modal success rate is the proportion of the success cases among the relevant possible situations in which the agent intends to $\phi$. The agent's quota of successful performances in the actual world, in contrast, is what we can call her track record ${ }^{2}$ : it is the proportion of the success cases among the actual intention situations.

The agent's track record plays a heuristic role. By looking at an agent's track record, we find out about situations in which the agent's intentions were successfully realized and situations in which they weren't. That gives us good reasons to infer certain beliefs about patterns of success across possible worlds. In the end, though, it's the modal success rate that counts.

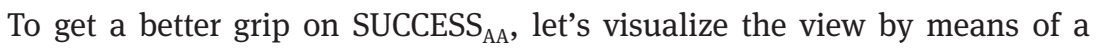
Venn diagram.

2 I borrow this term from Greco (2007: 60f.) 


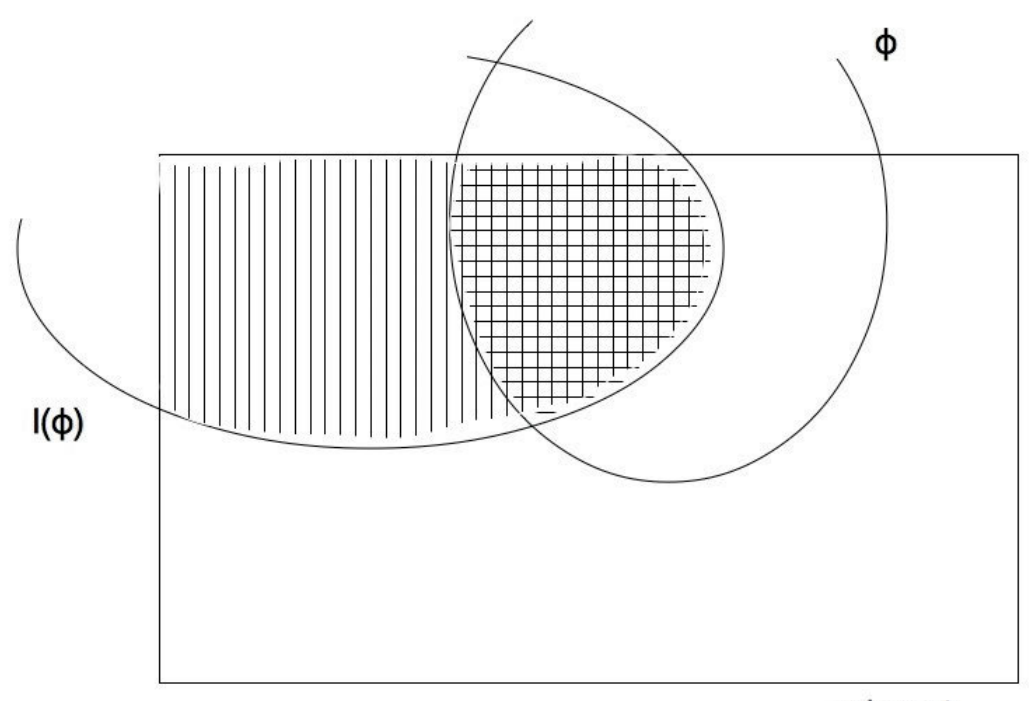

relevant

What matters for an agent's agentive ability to $\phi$, according to SUCCESS $_{\mathrm{AA}}$, is the proportion of $\phi$-ing cases among the relevant intention situations. In the diagram, we have the relevant possible situations in the box. In the vertically dashed area, we have the relevant intention situations. In the horizontally dashed area, we have the relevant intention situations in which the agent $\phi$ 's. What matters is the proportion of the horizontally dashed area among the vertically dashed area. If it is sufficiently high, the agent has the ability to $\phi$. If not, she lacks it.

Quite simple thus far. And quite intuitive, I hope. Let's dive deeper. Thus far, I have only emphasized the similarities between SUCCESS AA $_{\text {and the conditional }}$ analysis; both stress the importance of a certain modal link between the agent's intention to $\phi$ and the agent's effective performances of $\phi$-ing. But a second glance at SUCCESS $_{\mathrm{AA}}$ reveals that the condition also draws on an important idea of possibilism. For what matters for an agent to have an ability, according

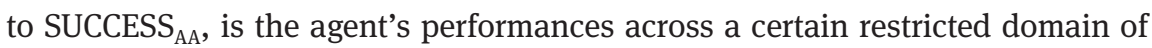
possible situations. And this feature is something the view obviously shares with possibilism.

While the proponent of the simple conditional analysis always moves to the intention worlds that are overall closest to the actual world, the possibilist restricts the possible worlds in correspondence to whatever features of the actual world are of interest in a given context and evaluates the agent's performances in any of those worlds. The exact same procedure is used in the case of SUCCESS $_{\mathrm{AA}}$ : 
we first determine the relevant possible situations. For this reason, I will often employ Kratzer's terminology and refer to the relevant possible situations as the modal base and to the facts that determine that modal base as the facts "in view of which" the agent has an ability.

Note that SUCCESS $_{\mathrm{AA}}$ speaks of situations where possibilism speaks of worlds. That is because what matters, according to SUCCESS $_{\mathrm{AA}}$, is the ratio of performances of $\phi$-ing to intentions to $\phi$. Worlds, of course, can contain many instances of intending to $\phi$. When we think about the ratio of performances to intentions, all of those instances count. That is why worlds are not fine-grained enough to figure in SUCCESS $_{\mathrm{AA}}$. For this reason, SUCCESS $\mathrm{AA}_{\mathrm{AA}}$ is formulated in terms of situations. A situation, as I use the term, is a proper part of a world. It is a world at a certain stretch of time.

Which situations go into the modal base will vary. Like possibilism, SUCCES$\mathrm{S}_{\mathrm{AA}}$ is a contextualist view about abilities in the sense that the set of the relevant possible situations varies across contexts. Let's make this explicit. SUCCESS ${ }_{\mathrm{AA}}$, as I will defend it in the course of this book, is to be understood as the view that

SUCCESS $_{\text {AA_context }}$ an agent $S$ has an agentive ability to $\phi$ if and only if $S \phi$ 's in a sufficiently high proportion of the relevant possible situations in which she intends to $\phi$, where the set of the relevant possible situations will vary across ascriber contexts.

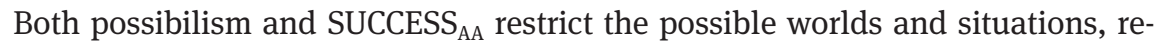
spectively, to the ones that count as relevant in a given context, then. In both cases, certain facts of the actual world are held fixed across modal space. Others vary wildly. Sometimes, any situation will count as relevant in which the agent's intrinsic features are as in actuality. Sometimes, to count as relevant, a situation will additionally have to resemble the actual situation with respect to varying sets of extrinsic features of the agent.

In connection with possibilism, we have seen that this contextual restriction to different sets of worlds in terms of relevance took us quite a few steps towards an account of more or less general or specific abilities. As we'll see later on in some detail $(\rightarrow 4.5)$, SUCCESS $_{\text {AA }}$ preserves this extremely fruitful feature of possibilism, but moreover provides the resources for a full-fledged account of general and specific abilities.

There are two important differences between SUCCESS $_{\mathrm{AA}}$ and possibilism. First, in contrast to the possibilist, we do not look at the agent's performances across all relevant possible situations, but only across a certain subset of those situations. The link between intentions and performances, which is also what proponents of the simple conditional analysis are after, is established by 
adding a second restriction on the situations that count. What matters is not just the agent's performance across the relevant possible situations in general, but rather across the relevant possible situations in which the agent intends to $\phi$. This second restriction, which is clearly not part of the possibilist framework, is what secures the modal link between intentions and performance. But it does so by a core means of possibilism - by imposing restrictions on the modal realm.

The second difference is that according to SUCCESS $_{\mathrm{AA}}$, the possibilist is wrong in assuming that abilities can be analyzed in terms of the possibility operator. While abilities are indeed a matter of the agent's performance across relevant possible situations, one performance case is rarely enough. That is why possibilism ran into the destructive formal problems we looked at and had trouble accounting for general abilities and degrees. Possibilists get the modal force of ability statements wrong; ability statements are not possibility statements.

What is the right modal force? On my view, abilities have to be understood in terms of what we can call "proportional quantification": there has to be not one, but a sufficient proportion of relevant intention situations in which the agent $\phi$ 's.

What does "a sufficiently high proportion" amount to? That will vary - and rightly so. We know that there is context sensitivity involved in the degree of an ability that is required for an ability ascription simpliciter to apply. And as I will lay out in due course $(\rightarrow 4.3$ ), the (weighted) proportion of performance cases among the relevant intention situations corresponds to the degree of an agent's ability. More specifically, I will argue that the higher the (weighted) proportion of performance cases is among the relevant intention situations, the higher the agent's degree of ability. And so, since it varies which degree of ability is required for the agent to count as having the ability simpliciter in a given context, it will also vary which proportion of performance cases counts as sufficient.

Despite some important similarities, then, SUCCESS ${ }_{\mathrm{AA}}$ differs substantially from possibilism. What remains to be done is to set the view apart from the simple conditional analysis a bit more carefully as well. The major difference between the success view and the simple conditional analysis is that the success view is not formulated in terms of a counterfactual conditional. Now that we have a grip on the idea of proportional quantification and the restriction to relevant possible situations that figures so prominently in SUCCESS, it should be easy to see that this difference has far-reaching consequences.

By formulating the simple conditional analysis in terms of a counterfactual, the proponent abilities are analyzed in terms of the agent's performance in the closest worlds in which the agent intends to $\phi$. An agent has an ability to $\phi$, on that view, if and only if the agent $\phi$ 's in the closest worlds in which she intends to $\phi$. SUCCESS $_{\mathrm{AA}}$ is at the same time more liberal and more restrictive than 
that. It is more liberal since the agent need not $\phi$ in the closest intention situations. A $\phi$-ing performance in one of the less close, but still relevant intention situations is just as valuable as in the very closest ones. At the same time, SUC$\mathrm{CESS}_{\mathrm{AA}}$ is more restrictive, because in most contexts one performance case just won't do, no matter how close it is: the agent has to $\phi$ in a sufficient proportion of the relevant intention situations, and as we will see later on $(\rightarrow 4.3 ; 4.5)$, that will usually require that she $\phi$ 's in more than just one situation.

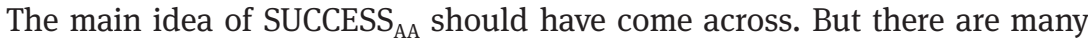
details which are going to be provided as we go along. In the next section $(\rightarrow$ 4.2), I'll talk about the notion of an intention and provide a rationale for formulating the view in terms of that motivational state and not another. Afterwards, in sections 4.3-4.7, we'll see that the success view is very powerful. Rightly developed, it delivers a fully comprehensive account of agentive abilities, which accounts for all of the adequacy conditions for a comprehensive view of such abilities and does not run into any of the problems that beset the simple conditional analysis and possibilism, respectively.

\subsection{The proper motivational state}

The success view shares one important feature with the simple conditional analysis: both stress the importance of a certain modal link between the agent's intentions to $\phi$ and the agent's effective performances of $\phi$-ing. When I introduced the simple conditional analysis, I said that different versions of the view differ with respect to the motivational state that figures in the antecedent of the counterfactual. Different versions of the view feature motivational states as diverse as trying, intending, wanting, choosing, and desiring. For reasons of exposition, I did not dwell on those differences, but focused on the similarities between the various versions instead. For plasticity, I just picked one motivational state and formulated the simple conditional analysis in terms of intentions. But I could just as well have formulated it very broadly as the view that an agent has an ability to $\phi$ if and only if the agent would $\phi$, if the agent were properly motivated to $\phi$.

I could have availed myself of the same non-committal formulation in my formulation of SUCCESS AA $_{\text {. SUCCESS }}$ AA could have been formulated as the view that an agent has an agentive ability to $\phi$ if and only if the agent $\phi$ 's in a sufficiently high proportion of relevant possible situations in which the agent is properly motivated. Instead, I have chosen a more committal formulation: SUCCES$\mathrm{S}_{\mathrm{AA}}$, as I have formulated it, postulates a modal tie between a particular kind of motivational state and the agent's performances. What counts, on my view, 
is the tie between the agent's intention to $\phi$ and her effectively $\phi$-ing. In this section, I will elaborate a bit on the notion of an intention, as it figures in the analysis, and on the rationale for focusing on intentions and not some other candidate motivational state.

An intention, as I am using the term in the course of this book, is simply an action-initiating propositional attitude in the sense that it is part of its causal role that it will typically initiate behavioral episodes corresponding to its content. I will assume that the behavioral episodes which are caused by intentions (in the right way) $)^{3}$ are actions. Further, I will assume that it is the causal impact of an intention that explains the intentionality of an action. I hope to be firmly ensconced in the action-theoretical common sense or at least the respectable tradition with these assumptions.

We can differentiate between intentions to $\phi$ right away and intentions to $\phi$ in the future. Intentions, as they figure in SUCCESS $_{\mathrm{AA}}$ are intentions to $\phi$ right away. Intentions to $\phi$ in the future can be given up, and it therefore does not count against an agent's ability, if an agent intends to $\phi$ in the future, but does not $\phi$ when the time comes. So "intention", as I use it, is always the intention to $\phi$ at $t$, where $t$ is, roughly, the next moment.

Let me now talk about the rationale for focusing on intentions, so understood, and not some other candidate motivational state. First, the motivational state figuring in the account has to be action initiating the sense that it will typically lead to action. A state that is motivational but not action-initiating in this strong sense will not do. To see that, take ordinary desires. Desires are motivational, but not action initiating. They constitute, qua desire, a mere prima facie motivation towards the desired action. This has two reasons.

On the one hand, desires can be overridden by other desires. I can have a desire to go dancing, but that desire can be overridden by an even stronger desire to go to sleep (yes, I am getting old). In that case, dancing will not be the favored course of action. Instead, I'll presumably end up curled up in my bed. On the other hand, desires alone will not do anyway; without a proper belief, no action will ensue. Even an overriding desire to go dancing will only result in dancing, if I believe that there is a party somewhere. Otherwise, I'll end up sleeping all the same.

These features of desires indicate that desires are not the suitable motivational states to figure in an account of abilities. My not acting on a desire to

3 "In the right way" means "by non-deviant causal chains". How to think of non-deviance is a problem of action theory and falls outside the scope of this book. For an overview see (Wilson \& Shpall 2012, section 2). 
go dancing, which is either overridden by an opposing desire or paired with an action-inhibiting belief, does not speak against my ability to go dancing. That is why the success view cannot be formulated in terms of desires or any other merely prima facie motivating state, such as wants. We get distorted results, if we evaluate the proportion of dancing cases among the relevant possible situations in which the agent is merely prima facie motivated to dance. Any situation in which the agent has an overriding desire or want to go to sleep or believes that there is no party around, would have to be counted against the agent's ability to dance. Certainly, this is the wrong outcome. What we need is an action-initiating state: a state which typically initiates action. Intentions are just that.

Yet, the need for an action-initiating state does not rule out a number of different motivational states. It does not speak against a formulation of the success view in terms of choices, decisions, tryings, or attempts, for instance. To see why those motivational states are ill-suited to figure in the analysis, we need to focus on a different requirement that goes along with a satisfactory formulation of an account of agentive abilities: the motivational state had better itself not be an action.

Otherwise, a regress looms. The success view, as it stands, is supposed to offer an account of agentive abilities - abilities to perform actions. The way the view aims at this goal is by postulating a modal tie between a suitable motivational state to perform some action on the one hand and the effective performance of the action on the other. If this is true, however, then the motivational state figuring in that modal tie had better not itself be an action. Otherwise, one will rightly wonder what it is for the agent to have an ability to perform that kind of action.

For illustration, let's assume that the success view were formulated as the view that an agent has an agentive ability if and only if the agent $\phi$ 's in a sufficiently high proportion of relevant possible situations in which the agent tries to $\phi$, and let's assume, as many have, that trying is an action. ${ }^{4}$ Then the question will naturally arise what it is for an agent to have the ability to perform that action: what is it for an agent to have the ability to try?

For the proponent of the success view, the only reasonable available answer is to state that an agent has an ability to try if and only if the agent tries in a sufficiently high proportion of the relevant possible situations in which the agent tries to try. And so on. Ad infinitum, with ever less plausibility. ${ }^{5}$ The same goes for choosing, deciding, attempting, and any other motivational

4 See for instance Adams (1994).

5 Note that Moore (1912, ch. 7) does not seem to think that there is any problem with this. 
state that seems to be an action itself. We can conclude that the success view had better be formulated in terms of a motivational state that is itself clearly not an action. Intentions, I take it, meet this requirement.

\subsection{An account of degrees and context sensitivity}

In this and the next four sections, I will, piece by piece, demonstrate the merits of SUCCESS $\mathrm{AA}_{\mathrm{AA}}$. In this section, I will turn to the way the success view accommodates degrees of abilities and the corresponding kind of context sensitivity that attaches to ability statements. Providing an understanding of those phenomena is a central task in developing a viable account of abilities. In fact, it is one of the adequacy conditions for a comprehensive view of abilities. As I have laid out in chapter 1.3, any comprehensive view of abilities will have to accommodate degrees and the corresponding kind of context sensitivity of ability statements.

On the view I will lay out in this section, the crucial tool provided by SUC$\mathrm{CESS}_{\mathrm{AA}}$ is the notion of the agent's modal success rate. Roughly, we can say that the higher the proportion of $\phi$-ing cases is among the relevant intention situations, the higher the degree of an agent's ability. ${ }^{6}$

Let's recall that abilities can be graded along two dimensions. On the one hand, there is the dimension of reliability. It can count, towards the degree of an agent's ability, how large the range of the circumstances is in which the agent manages to perform an action. On the other hand, there is the dimension of achievement. It can count, towards establishing the agent's ability, how high the quality of the agent's performance of an act is that the agent manages to deliver.

In what follows, I'll give an account of both dimensions individually, but on top of that I'll also sketch an account of agents' degrees of abilities quite generally. That means that I'll give an account of degrees which holds, no matter which dimension carries which weight. It thus unifies the two dimensions and reveals a way to think of a mechanism of how to set them off against each other in contexts in which they are set off.

The account of degrees of reliability is quite easily developed. SUCCESS $\mathrm{AA}_{\mathrm{AA}}$ is tailor-made for the understanding of degrees along that scale. Reliability has to

6 A very similar account is developed for degrees of dispositions by Manley \& Wasserman (2008). Manley and Wasserman's account is a very sophisticated version of the conditional analysis, but it also features the notion of proportions of (centered) worlds and uses that notion to account for degrees. See also Maier (2013). Both accounts are going to be discussed in detail later on $(\rightarrow 6.2,6.4)$. 
do with the range of possible circumstances in which an agent manages to perform a certain action. The modal success rate measures just that: the range of the possible circumstances in which the agent's intentions are followed by the corresponding action. Thus, the modal success rate is the measure for reliability. The more reliable archer is one who hits the target in a higher proportion of relevant possible situations in which she intends to hit it. The more reliable weather forecaster is one who predicts the weather correctly in a higher proportion of relevant possible situations in which she intends to predict the weather. And so forth.

At first sight, it is not obvious that SUCCESS $_{\mathrm{AA}}$ accounts equally smoothly for the dimension of achievement. To see the issue, think of the two pianists, one of whom plays perfectly on every occasion, while the other one plays poorly on every occasion. On the dimension of achievement, the first pianist is better. But prima facie, this dimension does not fit well with the success view. The notion of being better in terms of achievement seems to be essentially qualitative. It does not seem to have to do with the range of cases in which one performs at all. What counts is how well one performs. And that, it might seem, cannot be accounted for in terms of the purely quantitative measure that is given by comparing proportions of cases in which performance takes place. In a nutshell: the modal success rate in $\phi$-ing does not seem to be qualitative enough to account for the dimension of achievement.

Fortunately, this is less of a problem than it may seem at first sight. Proportions matter. But not every $\phi$-ing case is counted equally when it goes into the proportion of $\phi$-ing cases among the relevant intention situations. Instead, we need to weigh the cases we are counting. ${ }^{7}$ Here is how.

The qualitative dimension that enters in on the level of achievement can be modeled quantitatively by giving certain situations a higher value the closer the performance in those cases comes to some (contextually determined) ideal. The idea behind this is simple. If someone plays a piano piece flawlessly, that counts more towards her ability to play the piano than her playing the same piece badly. If someone plays a piece with verve and emotion, that counts more towards her ability to play the piano than if she plays the same piece like an automaton. And so forth. This notion of "counting towards the ability" can be captured by adding extra value to a situation the more the performance in that situation counts towards the ability in question. The more verve an agent's play exhibits in a given

7 This is also suggested by Manley \& Wasserman (2008) in connection with the gradability of dispositions. In assessing the fragility of a vase, it is not only important in which proportion of stimulus worlds it breaks, but also how extensively it breaks. Apparently, shattering counts more towards an object's fragility than cracking. 
case, the higher the value we attach to that case. The less mistakes an agent makes in a given case, the higher the value we attach to those cases.

Depending on the context, it will vary which qualities matter most. In some contexts, flawlessness is the major virtue we are after. In others, verve is more important. This is mirrored in the values we attach to the cases. The more important verve is, the more value we attach to the verve-cases. The more important flawlessness is, the more value is given to the flawlessness-cases. And so on. We can think of that in terms of numbers. An ideal performance gets a 1 . A performance that is too miserable to count as an act of $\phi$-ing at all gets a 0 .

When is an agent better on the achievement level? That depends. Sometimes, all that matters is her best performance across the relevant intention situations. When we are evaluating two piano players' abilities to play a certain piece, we may sometimes be willing to count that agent more able on the achievement level who manages to deliver the best performance, no matter how miserably the agent plays in most other cases. In such cases, the highest value wins, so to speak.

Perhaps there are also contexts in which the lowest achievement value is what counts. It is not implausible, for instance, that there are contexts in which an emergency doctor's ability to prevent damage is counted as higher the fewer people die under her care and not the more people come out completely healed in the end. In such contexts, the higher the lowest value of cases in which damage is prevented, the better the doctor on the achievement level.

Finally, there also seem to be cases in which we are interested in the average value of the agent's performances. Usually, a hedge fund manager who plays full-risk all the time and wins a fortune every once in a while losing huge amounts of money in most cases does not count as better, in terms of achievement, than someone who plays it cool and wins a few percentages in each transaction. Here, what often counts seems to be the average achievement value.

Which achievement value is of interest in a context can vary and often we will have to set the dimensions off against one another. A very high peak value will sometimes outweigh a poor average and a devastating off-peak value. But likewise, a very low off-peak can outweigh a good average value and an amazingly high peak value. Let's assume, for the time being, that the average value is always what counts. I'll come back to the interplay between the various achievement values in due course.

Let's take stock. What we have is an account of both degrees of reliability and degrees of achievement. An ability's degree of reliability corresponds to the proportion of relevant intention situations in which the agent performs the intended action. An ability's degree of achievement corresponds to whatever achievement value matters to us, but for the time being we assume it corre- 
sponds to the average achievement value of the agent's performances. Sometimes, we are interested in reliability only. Sometimes, in achievement only. Which of the two matters varies with the kind of ability we are considering, and presumably also with other context factors. So far, so good.

In many cases, however, this is not enough. Very often - in fact: usually - we are not just interested in one of the two dimensions. Usually, an agent's overall degree of an ability depends on both her degree of reliability and her degree of achievement. What we really want, then, is a unified account of degrees, taking into account both the dimension of reliability and the dimension of achievement at once. We want what I would like to call a weighted proportion ${ }^{8}$ - a value that is higher the better someone performs in the more cases.

Obviously, there are various ways of generating such a value, but not all of them work equally well. For instance, we will have to make sure that reliability and achievement as a whole can be of unequal importance for the degree of an agent's ability. Sometimes, reliability is what matters most. Sometimes, achievement.

Here is a toy model for the way in which the two dimensions might be set off against each other. In a first step, we evaluate the dimension of reliability. We determine the proportion of $\phi$-ing cases among the relevant intention situations. The higher the proportion, the higher the number. In a second step, we determine value for the agent's achievement. For simplicity, we are working with the average value, and that value is obtained by adding the values for the agent's individual performances and dividing it by the number of relevant intention situations. The situations in which she does not perform at all get a 0 .

We can now add these values. But before we actually add them, we have to determine how much weight to put on each value. We can do this by using a multiplier. Let $\mathrm{m}$ and $\mathrm{n}$ be multiplier variables. Let $\mathrm{R}$ be the value for reliability. Let $\mathrm{A}$ be the value for the agent's achievement. Then the agent's success rate, SR, will be determined along the following lines:

$$
\mathrm{SR}=(\mathrm{m} \times \mathrm{R})+(\mathrm{n} \times \mathrm{A})
$$

If we are interested in reliability only, we set $n=0$. If we are interested in achievement only, we set $\mathrm{m}=0$. If we are interested in both, we weigh them by attaching to each a multiplier that suits our focus. By that procedure, we obtain the weight-

8 I borrow this term from Manley \& Wasserman (2008). Manley and Wasserman give no account of how the correlates of reliability and achievement are to be set off in the case of dispositions, but as far as I can see, they, too, will need something like the toy model I will suggest for degrees of abilities. 
ed proportion we were after - a value that is higher the better the agent performs in the more situations and in which the dimensions of reliability and achievement can be set off against each other according to the focus we put on each dimension in a given context.

By the same kind of procedure, we can determine the agent's overall achievement value, by the way. The challenge, recall, was basically the same: the agent's achievement often depends on a variety of values - the peak value, the off-peak value, and the average value of the agent's performance. Obviously, this interplay can be modeled along the same lines as the interplay between achievement and reliability as a whole. We can simply add all of the values which count and determine the extent to which they go into the sum by attaching appropriate multipliers to each of them beforehand. Whatever overall value comes out for the agent's achievement is the one we are inserting into the formula for the agent $\backslash$ s overall success rate in $\phi$-ing.

I should emphasize that I am not arguing that we really do this kind of calculation when we evaluate an agent's degree of ability. What I have described as a calculation procedure is not really a procedure that falls into distinct steps. In fact, it is not even a procedure at all. It is a toy model of degrees of abilities in a possible worlds framework. It gives us an idea of how the notion of degrees of abilities, though highly qualitative in that it involves how highly we appreciate a given performance in a given context, can nevertheless be modeled in quantitative terms: as a numeric measure we project onto possible situations and which will change across contexts, depending on the one hand on our standards for what counts as a performance of $\phi$ at all, what counts as a good or bad performance, and what counts as a brilliant performance, and on the other hand on how important reliability and achievement are, respectively.

In virtue of the fact that the model is for illustrative purposes only, it is not of crucial importance that you agree with every detail of it. Perhaps you think there is more to be said about the dimension of achievement; perhaps you think that my discussion of the exemplary cases is not fully satisfactory; perhaps you have other quarrels with the details of the account. That is okay. As long as those quarrels do not concern the structural ingredients of the account (i.e. an account of degrees in terms of weighted proportions), I am fine with that. The ways in which we grade abilities are obviously very complex, and my account in terms of the two dimensions and the ways in which they are set off against each other is perhaps too coarse to account for every single way in which two agents' degrees of ability can vary. So be it, then.

What matters is that the basic notion of the success view, the notion of a success rate, is structurally suited to account even for the qualitative parts of our thinking about degrees and can account for the fact that various different dimen- 
sions, such as achievement and reliability, go into our calculations when we evaluate an agent's overall degree of ability. Proportions matter - all we have to do is weigh the cases that are counted in an appropriate way. What I have outlined is one structural idea of how to do so. There may be other ways, and there may definitely be ways to improve the model I have sketched. I am content if my understanding of degrees is structurally on the right tracks, and I believe it is.

Here is the upshot of this section. According to the success view of ability, an agent has the ability to $\phi$ only if the agent $\phi$ 's in a sufficiently high proportion of relevant possible situations in which she intends to $\phi$. In the preceding paragraphs, I have elaborated on the right understanding of "proportion". What matters is not just the sheer number of $\phi$-ing cases. Rather, "proportion", as it occurs in the formulation of the success view, has to be interpreted as the weighted proportion that corresponds to the weighed sum of both, the agent's reliability value and her achievement value. The weighing is a matter of context. Sometimes, reliability counts more. Sometimes, achievement. The success view accounts for that.

Context sensitivity costs nothing on this picture. Once we have the scale established by varying success rates, and hence varying degrees of ability, the context simply sets a threshold on that scale. The threshold is provided by the notion of sufficiency. For an agent to have an ability simpliciter in a given context, the agent has to exhibit a sufficiently high weighted success rate in $\phi$-ing. And which weighted success rate counts as sufficient will vary. In what follows, I will not speak of the weighted proportion and success rate anymore. I take it to be clear that "proportion" and "success rate" have to be understood along those lines, and I trust that the reader will bear it in mind.

\subsection{Impeded intentions and the existential requirement}

SUCCESS $_{\mathrm{AA}}$ analyzes abilities in terms of a modal tie between intentions and performances. In this respect, it resembles the simple conditional analysis rather closely. For this reason, one very pressing question is whether SUCCESS $_{\mathrm{AA}}$ may not actually fall prey to the problem of the impeded intention as well. In view of the fact that the postulation of the counterfactual tie gave rise to the problem of the impeded intention in the case of the simple conditional analysis, the postulation of a very similar tie may seem like a very bad idea.

To evoke the problem, recall that the counterfactual tie between the agent's intentions and performances postulated by the simple conditional analysis is obviously not sufficient for an agent to have an ability. Reconsider Betty, our coma patient. For Betty, the counterfactual comes out true: she would raise her arm if 
she intended to raise it. That is because the closest worlds in which she intends to raise her arm are worlds in which she is not in a coma. And in those worlds, she would presumably also raise her arm.

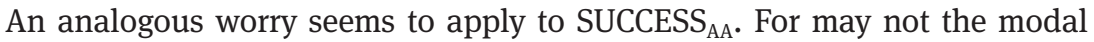
success rate be quite high in the case of a coma patient? The agent's intention to raise her arm will only occur in situations in which the agent is not in a coma, after all. And in such situations, nothing impedes her raising her arm. Hence, it seems as though the modal success rate will be averagely high for

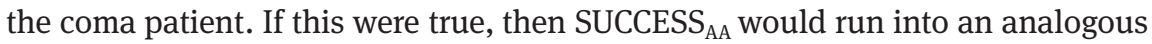
problem as the simple conditional analysis: the modal success rate is averagely high, while the agent lacks the ability, because she cannot form the intention to begin with. Like the simple conditional analysis, the condition stated in SUCCES$\mathrm{S}_{\mathrm{AA}}$ would turn out to be insufficient in that case.

Luckily, this objection relies on a misunderstanding of SUCCESS $_{\mathrm{AA}}$. SUCCES$\mathrm{S}_{\mathrm{AA}}$ states that to have an agentive ability to $\phi$, the agent has to $\phi$ in a sufficiently high proportion of relevant possible situations in which she intends to $\phi$. This condition is not met in the case of the coma patient. In contexts in which we want to say that the coma patient lacks the ability to raise her arm, the set of relevant possible situations will contain only situations in which the agent is in a coma at the outset. But among those situations, there will be no intention cases to begin with. And from this it follows that there will not be a sufficiently high proportion of performance cases among the relevant intention situations. Let me explain.

When there are no relevant intention situations, to determine the proportion of performance cases among the relevant intention situations, one would have to determine the proportion of performance cases among the empty set. And depending on the exact mathematical understanding of "proportion", that proportion will either be unspecified or zero. Either way, it will not be the case that there is a sufficient proportion of performance cases among the relevant intention situations. SUCCESS ${ }_{\mathrm{AA}}$ fails to be met either way, then.

Let me elaborate on this last point in some more detail. First, let's recall that SUCCESS $_{\mathrm{AA}}$ applies proportional quantification to the relevant intention situations. What SUCCESS AA $_{\text {A }}$ states is that an agent has an ability if and only if there is a sufficiently high proportion of performance cases among the relevant intention situations. This condition can be violated in two ways. It is violated, first, if there is no proportion of performance cases among the relevant intention situations to begin with. It is violated, secondly, if there is a proportion, but the proportion is not sufficiently high. Depending on how exactly we spell out the notion of a proportion, SUCCESS ${ }_{\mathrm{AA}}$ will fail to be met on either one of those two grounds. 
If "proportion" is spelled out as a ratio, as I have done in terms of the modal success rate, then the proportion of performance cases among the relevant intention situations will be unspecified, if there are no relevant intention situations to begin with. We are dividing by zero in that case. To see that, let $I$ be a value representing the size of the set of the relevant possible situations in which $\mathrm{S}$ intends to $\phi$. Let $P$ be a value representing the size of the set of the performance cases among those intention situations. Given the interpretation of a proportion in

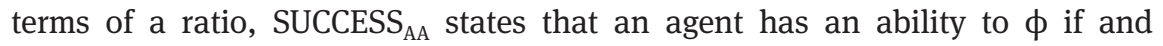
only if

SUCCESS $_{\text {AA_ratio }}$. there is a value $\mathrm{v}: \mathrm{v}=\mathrm{P} / \mathrm{I}$, such that $\mathrm{v}$ is sufficiently high.

From this, it follows that the proportion of performance cases among the relevant intention situations is unspecified in the coma case. In the coma case, the value for I is zero. It will thus not be true that there is a sufficient proportion of performance cases among the relevant intention situations. There is no such proportion. SUCCESS ${ }_{\mathrm{AA}}$ is therefore not met in this case.

If "proportion" is given a less formal interpretation - an interpretation along the lines of a share or a part, say - then one may be able to make sense of the notion of a proportion of cases among the empty set. Even so, however, that proportion can only ever be zero in that case. No subset of the empty set will ever contain anything. If that is true, then SUCCESS $_{\mathrm{AA}}$ will fail to be met on that interpretation of "proportion" as well, since the proportion of performance cases among the relevant intention situations will not be sufficiently high in that case. Zero situations just won't do.

We have just revealed an important entailment of SUCCESS $_{\mathrm{AA}}$. On any sensible interpretation of SUCCESS $_{\mathrm{AA}}$, SUCCESS $\mathrm{AA}_{\mathrm{A}}$ is only met if there is a relevant intention situation in the first place. In other words, the view entails that it has to be possible, in the properly restricted sense, for the agent to form the intention. Call this the existential requirement:

EX. An agent has an ability only if there is a relevant possible intention situation.

That SUCCESS $\mathrm{AA}_{\mathrm{A}}$ entails the existential requirement is a very welcome consequence. When we looked at the simple conditional analysis, we saw that a very natural way of responding to the problem of the impeded intention is to try and supplement the counterfactual by a further requirement. Not only does it have to be true that the agent would $\phi$, if she intended to $\phi$, she also has to be able to form the intention in the first place. The problem was that the proponent of the simple conditional analysis did not have the resources to explain 
what on earth the truth conditions for this supplementary claim were supposed to be.

The success view, in contrast, can do justice to that insightful intuition. It is true that for an agent to be able to $\phi$, the agent has to be able to form an intention to $\phi$ to begin with. And what is it for the agent to be able to form the intention? Well, as a minimal requirement, it is for the existential requirement to be true: there has to be a relevant possible situation in which the agent intends to $\phi$.

When the intention is impeded, the existential requirement is not met. Holding the coma fixed, there are no relevant intention situations to begin with. Hence, the proportion of hand-raising cases among the relevant intention situations is either unspecified (if a proportion is a ratio) or nil (on a less formal reading). Hence, SUCCESS fails to be met either way in such cases.

The same goes for the brainwashed follower of a cult. The agent cannot leave the cult, because she cannot form the intention to leave in the first place. SUCCESS yields exactly that. For the brainwashed agent, there is no sufficient proportion of situations in which the agent leaves the cult among the relevant possible situations in which she intends to do so. That is because there are no relevant possible situations in which she intends to leave the cult to begin with. The relevant possible situations will be situations in which the person is as brainwashed as she is. And since the brainwash prevents the person from forming the intention to leave, there will not be any situations among the relevant ones in which the agent intends to leave. The set of the relevant intention situations is therefore empty, and hence the proportion of the situations in which the agent leaves among the relevant intention situations is either unspecified or nil. The success view therefore rightly yields that she lacks the ability to leave the cult. Cases of an impeded motivation can be accounted for very smoothly, then.

Proponents of the simple conditional analysis who have followed my argument up to this point will probably perk up their ears right now. Doesn't an analogous treatment of cases of an impeded intention lend itself to them as well? Why can't proponents of the simple conditional analysis simply say that for an agent to have an ability, two requirements have to be met. First, it has to be the case that the agent would $\phi$, if she intended to $\phi$. Secondly, there have to be worlds in which the agent intends to $\phi$ and those worlds have to be similar enough.

That, it seems, solves the problem of the impeded intention. For while the counterfactual would still be met by the coma patient, the additional condition would not. Worlds in which the coma patient intends to raise her arm are simply too far out, given that the coma patient is actually in a coma. That, the proponent 
of the now somewhat less simple conditional analysis could say, is why the coma patient lacks the ability to raise her arm.

The account I have just sketched has actually been formulated in the literature. On Peacocke's (1999) account, S has the ability to $\phi$ if and only if the counterfactual is true of $S$ and the world in which $S$ tries to $\phi$ is close (309). Peacocke then spells out closeness in terms of what we can reasonably rely on. A world is close, on his account, if and only if we cannot reasonably rely on it not obtaining (ibid: 310). As it seems, then, the proponent of the simple conditional analysis can avail herself of roughly the same solution for the problem of the impeded intention, but the account would have to be extended considerably.

\subsection{An account of general and specific abilities}

In section 4.3, I have used SUCCESS AA $_{\text {to }}$ come up with an account of degrees of abilities and the corresponding context sensitivity of ability statements. In doing so, I have shown how one very important adequacy condition that spelled trouble for both the simple conditional analysis and possibilism is met by SUCCES$\mathrm{S}_{\mathrm{AA}}$. Let's now move on to the other adequacy condition. Any comprehensive view of abilities has to shed light on the distinction between general and specific abilities. Let's see what SUCCESS ${ }_{\mathrm{AA}}$ has to offer in this regard.

According to SUCCESS ${ }_{\mathrm{AA}}$, an agent has an agentive ability to $\phi$ if and only if she $\phi$ 's in a sufficient proportion of relevant intention situations. The important notion here is that of relevance. Which situations count as relevant in a given context varies. And these variances generate abilities that are sometimes general, and sometimes specific.

In the case of general abilities, we are interested in what an agent can do, independently of her current situation. Hence, we are interested in the agent's abilities in view of her stable, mostly intrinsic features. In such a case, the relevant possible situations will comprise any situation that resembles actuality with respect to those features. The temporary, extrinsic features of the agent's current situation are varied. In the case of specific abilities, in contrast, we are interested in what the agent can do in view of her very situation. Hence, the relevant possible situations will comprise only situations that are like actuality with respect to the features of the agent's current circumstances. Thus, we will also hold a large number of the temporary, highly extrinsic features of the agent fixed.

For illustration, consider Fred's ability to do a handstand. Does Fred have that ability when his arm is broken? That depends. In one sense, he does - he has had training, he has often done a handstand in the past, he rarely failed when he tried to do it. But in another sense, he cannot do a handstand. He 
can't do a handstand here and now, broken arm and all. In the terminology of general and specific abilities, this can be expressed by saying that Fred has the general ability to do a handstand, but not the specific ability.

SUCCESS $_{\mathrm{AA}}$ can account for all this. That is because the relevant possible situations will differ, depending on whether we are thinking about the general or the specific ability. When we are thinking about Fred's general ability, we are interested in what he can do in view of his muscular constitution and his sense of balance (plus background assumptions about the laws of nature, normality of the world, etc.). Thus, we abstract away from the broken arm and count all situations as relevant in which Fred resembles his actual self in terms of his sense of balance and his muscular constitution, say. Among those situations, there is a sufficient proportion of cases in which Fred does a handstand. SUC$\mathrm{CESS}_{\mathrm{AA}}$ therefore rightly yields that he has the general ability.

When we are interested in Fred's specific ability, we are interested in what he can do in view of his sense of balance, his muscular constitution and the fact that he has a broken arm. (Again, add the background assumptions. I won't mention that anymore as I go along.) Thus, we factor the broken arm in - only situations will count as relevant in which Fred's arm is as in actuality. Among those situations, Fred will not do a handstand in a sufficient proportion of intention situations. Hence, SUCCESS ${ }_{\mathrm{AA}}$ rightly yields that Fred lacks the specific ability.

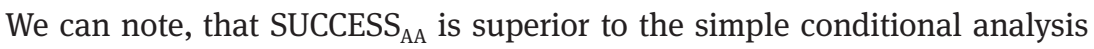
and possibilism when it comes to general and specific abilities. Unlike both views, SUCCESS ${ }_{\mathrm{AA}}$ accounts for the fact that general and specific abilities can come apart and that we are often willing to ascribe the general, but not the specific ability to $\phi$ to an agent. Moreover, it yields a unified account of ability statements, with general and specific abilities turning out to be essentially of the same kind. In contrast to both the simple conditional analysis and possibilism it thus has the advantage of meeting the second adequacy condition for a comprehensive account of abilities. It makes sense of the distinction between general and specific abilities and it elucidates their relation.

You will have noted that the account I just suggested avails itself of the very same mechanism the possibilist suggested for the treatment of general and specific abilities. According to the possibilist, recall, the difference between general and specific abilities is a difference in the sets of facts that go into the modal base. While we factor in lots of features of the agent's actual situation in the case of specific abilities, we only hold certain stable, mostly intrinsic features fixed in the case of general abilities. With respect to the agent with the broken arm, say, we hold the broken arm fixed when thinking about what the agent can do here and now, broken arm and all, but vary the fact that the agent has a broken arm when thinking about what the agent can do quite generally, inde- 
pendently of her current situation. Thus, the set of the relevant possible situations is going to vary, depending on whether we are interested in an agent's general or specific ability.

With respect to these features, my own account of general and specific abilities does not differ much from the possibilist's. I draw heavily on Kratzer's idea that the difference between the two kinds of abilities is essentially one of different modal bases. Yet, there is a very important difference, having to do with the kind of quantification that is applied to the relevant possible situations or worlds.

True to her name, the possibilist applies existential quantification to the possible worlds: to have an ability is for the agent to $\phi$ in one of the relevant worlds.

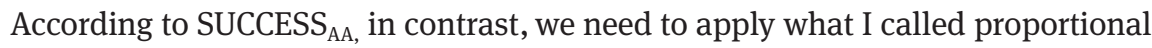
quantification: to have an ability, on this account, is for there to be a sufficient proportion of $\phi$-ing cases among the relevant possible situations in which the agent intends to $\phi$.

This difference matters a lot. For as we saw back in chapter 3.3, the possibilist eventually fails to account for general abilities. No matter how unrestrictive we are about the relevant worlds - no matter, that is, how few features of the actual world we hold fixed - for an agent to have a general ability to do a handstand, say, it is not enough for that agent to do a handstand in just one of the relevant worlds. For an agent to have a general ability to do pretty much anything whatsoever we expect her to show a somewhat reliable performance across various situations in those worlds.

Recall the characterizations of general abilities from several sources in the literature we looked at in the beginning in chapter 1.2. According to Whittle, a general ability is an ability to perform across a range of particular occasions. According to Honoré, a typist's claim to have the general ability to type amounts to the claim that "[s]he normally succeeds (...) when [s]he tries" (Honoré 1964: 465, my emphasis). And according to Maier, one's general ability “depends on one's relation to A in a wide range of circumstances" (Maier 2013: 11). This is where the kind of quantification matters. A single world just won't do. That is why according to SUCCESS ${ }_{\mathrm{AA}}$, an agent has an ability only if the agent performs in a sufficiently high proportion of the relevant possible situations. How large a proportion has to be in order to be sufficient can vary. But in the case of general abilities, one world will rarely do.

Thus, SUCCESS $S_{\mathrm{AA}}$ has two instead of just one parameter to account for the distinction between general and specific abilities. Not only does it vary which situations go into the modal base in each case, it also varies how large the proportion of performance cases has to be in order for the agent to have the relevant kind of ability. In part, the success view draws heavily on the tool box of the pos- 
sibilist, then. But it adds one crucial tool to the box. Only thanks to that additional tool is the success view capable of offering a complete account of general and specific abilities, whereas possibilism is bound to fail for structural reasons.

So far, I have given you the main outlines of the way I am thinking about general and specific abilities. Let me now provide you with some details. I will do so by discussing some of the ideas about general and specific abilities that have been floating around rather unsystematically in the literature.

\subsubsection{General abilities}

The most common way in which general abilities are distinguished from specific abilities is that agents have general abilities in virtue of their intrinsic properties alone, whereas they have specific abilities in virtue of intrinsic and extrinsic properties. Berofsky, for instance, writes that "[a]n individual possessed of a power (sic!) can take advantage of an opportunity by virtue of some intrinsic characteristic" (Berofsky 2002: 197). Basically the same point is made by Vetter, who holds that

the general ability to serve is possessed by an agent if and only if that agent has certain intrinsic features that enable her to serve; it does not depend on the agent's external circumstances. Her specific ability, on the contrary, is gained and lost with changes in her external circumstances (...). Her general ability to serve is an intrinsic property of the agent; her specific ability is an extrinsic property. (Vetter ms.)

In this passage, Vetter suggests that the generality of an ability and its intrinsicality are two sides of the same coin. Having a general ability is for the agent to have some set of intrinsic properties. At first sight, this seems very reasonable, given the core idea of generality we identified: a general ability is an ability that is independent of the agent's specific situation. And if it is independent of the agent's specific situation, then it has to depend on intrinsic properties of the agent alone. Quod erat demonstrandum. A close tie between generality and intrinsicality also seems reasonable in view of some classic examples: the ability to serve depends solely on the way the agent is constituted. The ability to walk, sing, or cook as well.

Yet, I submit that intrinsicality is not the crucial feature when it comes to general abilities. To see that, note, first, that there are lots of intrinsic features we vary when considering an agent's general abilities: we vary the broken leg when thinking about the ability to jump, the current nervousness when thinking about the ability to meditate, and the drugged brain when thinking about the ability to solve a mathematical puzzle. We therefore certainly don't hold all in- 
trinsic features of an agent fixed when it comes to general abilities. Of course, Berofsky and Vetter do not suggest that we do. What they seem to be saying is just that we hold only intrinsic features of the agent fixed.

But that, too, seems very questionable. There are clear examples for what we would intuitively count as general abilities which do not depend on intrinsic properties of the agent alone. The ability to baptize. The ability to impress John. The ability to recognize a particular building. All of these abilities are fully general in the sense that we do not have a particular situation in mind when ascribing them and having them requires that the agent manage to exercise them across a large range of circumstances. Yet, all of these abilities depend as much on extrinsic properties of the agent as they depend on her intrinsic properties. The ability to baptize depends in part on the social practices in which the agent is embedded. The ability to impress John depends a great deal on John. And the ability to recognize a building depends to a large extent on the look of the building. As it seems, then, the relation between the generality of an ability and its dependence on intrinsic properties of the agent is not as tight as Vetter and Berofsky suggest.

That is why I have stated my account of general abilities in terms of stable, mostly intrinsic features of the agent. Stability, I submit, is what plays the key role. When we are thinking about what the agent can do independently of her situation, what we are holding fixed are features that the agent retains throughout a great number of situations. Those features will very often be intrinsic to the agent. But they need not be intrinsic to her; all that matters is that they are stable in the sense that the agent retains them across great changes of circumstance.

Which of the stable, mostly intrinsic features of an agent we hold fixed will vary. We may be interested in an agent's general ability sing on stage and hold fixed that the agent is so anxious of singing on stage that she immediately freezes as soon as she goes on stage. But we may also vary her nervousness. Each time, we are interested in one of the agent's general ability: an ability she has in view of some relevant set of stable, mostly intrinsic features of hers.

\subsubsection{Specific abilities}

Let's now look at specific abilities. We know that a specific ability is an ability to perform some action in some particular situation. I said before that this means that the facts of the situation will be held fixed in the modal base. But just which and how many of the facts of the situation have to be held fixed? Here, one can take various routes. As a result, one will get a whole spectrum of varyingly spe- 
cific abilities, all of which are legitimate in their own right, and none of which deserve privilege over the others.

Out of these many varyingly specific abilities, I will pick out three, because I take them to be particularly interesting. There are what I call particular abilities, which are abilities in view of the totality of facts obtaining at some specific time. There are what I call conative abilities, which are abilities in view of all but a few facts obtaining at some specific time - certain mental states of the agent are left undetermined in the set of facts that go into the modal base. Finally, there are what I call opportunities: abilities in view of the external facts, where it will to some extent be a matter of context which facts count as external. As we'll see, there is room for more classes of specific abilities, but the three I just mentioned seem to me to be the most prevalent ones.

Suppose I intentionally jump a fence. In a very good sense of "specific ability", my intentionally jumping the fence proves that I had the specific ability to jump the fence. For this to be so, I need not have a general ability to jump that fence; my jump a moment ago may have been the first and the last time I was and will ever be able to succeed - a wondrous fluke, a marvelous stroke of sheer luck. Yet, I did it, and so I was obviously able to do it at that moment.

This interpretation of specific abilities, though quite extreme in some ways, is quite well established in the literature. It is the sense of ability according to which each agent was able to do whatever they intentionally did and unable to do what they intended but failed to do. It is the sense of ability Geach has in mind when he says that "what a man does, he can do" (Geach 1957: 15). Following Honoré, it can be dubbed a "particular ability":

To summarize the use of 'can' (particular) in relation to particular actions: success or failure, on the assumption that an effort has been or will be made, is the factor which governs the use of the notion. If the agent tried and failed, he could not do the action: if he tried and succeeded, he was able to do it. (Honoré 1964: 464)

Particular abilities are fully in line with SUCCESS $_{\mathrm{AA}}$. They are abilities in view of the agent's total situation: what we need to hold fixed is the totality of features of the agent's circumstances. In the case of particular abilities, the relevant possible situations will narrow down to just one: the actual situation. ${ }^{9}$ The modal success rate will therefore become an all or nothing matter. If the agent intends to $\phi$ and succeeds, she has the particular ability, because she will thereby $\phi$ in a sufficient proportion - all - of the relevant intention situations. If she intends to $\phi$

9 I am assuming determinism here and throughout my discussion of particular abilities. 
but fails, she lacks it, because she will not $\phi$ in any of the relevant intention situations.

What if the agent cannot intend to $\phi$ in the first place in the actual world? Then she will lack the particular ability. Recall that one way for SUCCESS AA $_{\text {to }}$ be violated is for the relevant possible situations not to contain any intention cases to begin with. This is just what the existential requirement states. For an agent to have an ability, there have to be relevant intention situations - it has to be possible for the agent to intend to $\phi$ to begin with. If the relevant possible situations narrow down to the actual situation, as they do in the case of particular abilities, an agent therefore lacks the ability, if the actual situation is not an intention situation.

At first sight, this may strike you as strange. Come to think of it, though, it becomes apparent that it is not. To see that, note that we are talking exclusively about agentive abilities so far. If a situation is such that it is impossible for the agent to intend to $\phi$ in it, then it seems just right that the agent also cannot perform an act of $\phi$-ing in that very situation. In view of the fact that the agent cannot (in the properly restricted sense) intend to $\phi$, the agent cannot perform an act of $\phi$-ing. This is all as it should be. Actions are behavioral episodes brought about by an intention. Without an intention, no action can ensue. ${ }^{10}$ SUCCESS $_{\mathrm{AA}}$, including the existential requirement, yields the right verdict here.

I said that particular abilities are rather extreme in some ways. And they are. Specific abilities are abilities to $\phi$ in a particular situation. But of course, a situation can be individuated more or less finely. In the case of particular abilities, the situation is individuated in the finest possible way, namely by the totality of facts obtaining in a certain time span. We are holding absolutely every feature of the agent's circumstances fixed.

That need not be so, though. We may just as well think of a less extreme interpretation of specific abilities. We can be interested, for instance, in what the agent can do in the situation she is in, and yet abstract away from certain features of that situation. We may care about an agent's ability to swim here and now, say, but abstract away from the fact that the agent is strongly disinclined to swim (she does not want to get her hair wet and sees no reason in favor of swimming, say).

In the sense of a particular ability, the agent lacks the ability to swim in such a case. In view of her strong disinclination towards swimming, the agent cannot

10 Note that the notion of an intention at work here is not particularly challenging. The agent does not have to be aware of the intention, and the intention does not have to be a conscious state. 
form the intention to swim. But in a slightly less extreme sense, she may well have the specific ability: abstracting away from the fact that the agent has no inclination to go swimming, it may well be that there is a sufficiently high proportion of relevant intention situations in which the agent swims. Her intentional state is not held fixed, after all. Hence, the relevant possible situations will contain quite a few intention situations. And among those, there may well be quite a few in which the agent effectively swims.

For another example, consider a person who holds a firecracker and a lighter in her hands, but is anxious to light the firecracker. Does that person have a specific ability to light it? In the sense of a particular ability, she does not - in view of her current anxiety, she cannot intend to light it. There will not be any intention situations among the relevant possible situations. But according to a slightly less extreme interpretation, she does have the specific ability. Abstracting away from her current anxiety to light the firecracker, she can light it in the situation she is in. Holding fixed virtually every fact apart from her current anxiety, there are relevant possible situations in which the agent intends to light the fire cracker, and in a sufficient proportion of those situations, the agent will effectively light it.

Are those still specific abilities we are thinking about? I should think so. We are, after all, asking what the agent can do here and now, in some particular situation. The mere fact that we are abstracting away from some of the features of the situation - most commonly, the agent's temporary mental states - does not show that we are already in the realm of general abilities altogether. Specific abilities, I should think, can vary with respect to the completeness of the facts of the actual situation that go into the modal base. We can abstract from a small fraction of the features of the actual situation and yet be talking about an ability the agent has to $\phi$ in the very situation she is in.

I would even go as far as saying that we usually abstract from the facts determining the agent's motivational states when thinking about an agent's specific abilities. In this, I side with Berofsky, who writes that

[a] person who has the power to act may fail to do so for reasons having to do with her motivation or her will. (...) We normally distinguish between these [conative conditions] and the other conditions (ability, opportunity), regarding only the latter's absence as depriving one of the power to act. (Berofsky 2002: 196)

What Berofsky points out in this passage is that we normally do not count an agent as unable to perform some action in a particular situation just because the person is temporarily disinclined to perform that action or has other action-preventing motivational states. I take this to be exactly right. Specific abil- 
ities whose modal base does not contain the motivational states of the agent are therefore an important class of specific abilities. Following Berofsky's choice of words, I will call specific abilities of this kind "conative abilities".

To see how common conative abilities are, note that it is abilities of that kind which seem to underlie much of our thinking about whether or not agents could have done otherwise. "Could have done otherwise"-locutions create a context in which it is the agent's specific abilities, and not her general abilities, which are at issue. When I say "I could have asked for help", I am not just saying that I have the general ability to ask for help. Rather, I state that I had the ability to ask for help in the very situation I am picking out by my use of the past tense. It is specific abilities that matter. But the way we actually talk about things people could have done differently suggests that it is not particular abilities that are at issue in such contexts.

Take the disinclined swimmer once more. Usually, we will want to say that the agent could have swum - she just wasn't motivated to. Likewise in many other cases in which the agent's motivation is what prevents the act: the vegetarian could have eaten the meat, she just wasn't motivated to. The moral person could have stolen the wallet, she just wasn't motivated to. I could have asked for help, I just wasn't motivated to. What this shows is that we usually abstract away from agent's motivations when thinking about what the agent could have done differently. Since "could have done otherwise" locutions are very common in ordinary discourse, this shows that it is very often not particular, but rather conative abilities that concern us when we are thinking about agents' specific abilities.

Finally, let me talk about opportunities. What is an opportunity? Frankly, I don't think anyone has a clear idea. But I think Kenny is right when he points out that "an opportunity is something external” (Kenny 1976: 218). Thus, an opportunity for $\phi$-ing, in the most natural understanding of the term, will simply be favorable external circumstances for $\phi$-ing. The world outside the agent has to provide what it takes to perform $\phi$, so to say. If that is true, then for an agent to have an opportunity will simply be for the agent to $\phi$ in a sufficient proportion of intention situations in which the external circumstances of the situation are held fixed, according to the success view.

But what counts as external to the agent? Does a broken leg count as a lack of opportunity? Or does it simply prevent the agent from taking an opportunity? I take this to be rather unclear. Moreover, I take it to be unclear how many of the external features of the situation have to be taken into account. Does an agent have an opportunity to hole a putt when there is a bump in the grass which the agent does not see, and which will ultimately take the ball off course? Maybe. Maybe not. 
What this suggests is that the notion of an opportunity is context sensitive along two dimensions. Whether or not we count someone as having an opportunity will depend, first, on how completely the external facts of the situation go into the modal base, and secondly, it depends on which features we count as external to the agent in the first place. Depending on one's choices along those two dimensions, an opportunity may in some contexts simply come out identical to an agent's conative abilities - we hold everything fixed except the agent's motivational states. In other contexts, however, the modal base will not comprise the agent's broken leg. And this is surely something we want to hold fixed in the case of conative abilities.

Can having an opportunity also just amount to the having of a particular ability? I don not think this would be a natural interpretation of "opportunity". It would be rather odd to treat an agent's own motivational states - the agent's disinclination to swim, for instance - as something that deprives the agent of the opportunity to swim. It should be coherent, in any context, to say: "I had the opportunity, but I did not feel any inclination to take it". If the agent's motivational states entered the modal base of an opportunity in some contexts, then this would not be truly utterable in that context. I take it to be settled, therefore, that "opportunity" carries an at least somewhat external connotation and that the minimal requirement for circumstances to be external to an agent is for the circumstances not to comprise the agent's own motivational states.

\subsubsection{Dependence}

So far, we have looked at general and specific abilities individually. Let's now check how far the two depend on one another. We know that an agent can, in a given situation, have a general ability to $\phi$ without having the specific ability to $\phi$ in that very situation. This is one of the essential insights the distinction between the two is built upon. But what about the other way around? Does the having of a specific ability require that the agent also has the corresponding general ability?

Some authors seem to think so. Berofsky's concept of specific abilities (or token-abilities, as he calls them), for instance, seems to be simply that of an opportunity to exercise one of one's general abilities (Berofsky 2002: 196). To have a specific ability, then, the agent would have to have the general ability first. Whittle objects to this by pointing out that an agent may be perfectly able to jump 5 feet high in very specific circumstances, while at the same time being unable to jump 5 feet high across a large range of circumstances (Whittle 2010). This sug- 
gests that an agent may very well have a specific ability to $\phi$ without also having the corresponding general ability as well.

Who is right? Again, that seems to me to depend on one's use of "specific ability". The three types of specific abilities I characterized in the last section do not seem to require that the agent have a corresponding general ability.

Take particular abilities. My intentionally jumping the fence proves that I had the particular ability to jump the fence, irrespective of my having or lacking a general ability to jump the fence. My jump a moment ago may have been the first and the last time I was and will ever be able to succeed. Yet, I did it, and so I was obviously able to do it at that moment.

Likewise, in the case of conative abilities. Suppose a child holds a firecracker in her hand but has no intention to light it. Suppose further that the lighter she holds in her hand is extremely easy to handle, whereas the child is unable to operate most lighters. In that case, she has the conative ability, because she lights the fire cracker in a sufficiently high proportion of the relevant possible situations in which she intends to light it. The relevant possible situations will only contain situations that are like the actual situation in the non-motivational aspects of the situation, among them the fact that the child holds the easy-tohandle lighter in her hand.

Yet, the child lacks the general ability to light a firecracker, because in the vast majority of intention situations relevant for that ability she fails to light a firecracker. That is because the relevant possible situations will this time contain any situation in which the child is as in actuality with respect to her stable, intrinsic features. In the vast majority of those situations, she will get hold of lighters that are harder to operate. And hence, she will not light the firecracker in most of them.

Again, likewise in the case of opportunities. There is very good sense to be made of a once in a lifetime opportunity for committing the perfect crime - the circumstances being favorable this one time for getting away with what one did. Yet, this does not entail that the agent has a general ability to commit the perfect crime. Only some specific abilities will depend on the having of a general ability.

That is not to say that there is no good sense of "specific ability" which requires a corresponding general ability. We can define a solid particular ability as a compound of a general and a particular ability. Likewise, we can define a solid conative ability as a compound of a general and a conative ability. Finally, we can define a solid opportunity as a compound of a general ability and an opportunity, thus capturing what Austin (1956: 218) famously called the "all-in" sense of ability. As far as I can see, these are perfectly legitimate senses of "specific ability". And those senses do of course depend on the agent having the relevant general ability at the outset. 
What about the other way around? When I first introduced the distinction between general and specific abilities $(\rightarrow 1.2)$, I said that it is taken for granted that one can have a general ability without having a corresponding specific ability. In that sense, general abilities do not depend on specific abilities. But at the same time, it does not seem very plausible that one should have a general ability to $\phi$ without there being any possible situation in which one also has the specific ability to $\phi$. Quite to the contrary! When I have the general ability to sing, say, this seems to entail that there are various possible situations for which it is true that I have the specific ability to sing in those very situations. In this sense, general abilities do depend on the specific abilities.

This way of thinking about the relation of general and specific abilities is implicit in a number of passages in the literature, and in fact it seems to underlie the whole idea of the reliability of general abilities. When Whittle says that a specific ability requires that the agent be able to do something in particular circumstances, whereas a general ability requires that she be able to do it in a large range of circumstances (Whittle 2010), what she is saying is basically that one general ability goes along with many specific abilities. Maier is even more explicit on his commitment to such a picture: on his view, a general ability is actually constituted by a certain number of specific abilities - abilities to do something in particular situations (Maier 2013).

Maier and Whittle are on the right track here. General abilities to $\phi$ do require that there are situations in which the agent has a specific ability to $\phi$. I also think that it makes sense to think of general abilities as being made up of specific abilities. ${ }^{11}$ It would be overly complicated to go through all of the interpretations of specific abilities to show to what extent the having of general abilities depends on the having of each of the different kinds, but it can easily be shown that Whittle's and Maier's remarks make sense when it comes to particular abilities.

The argument for the claim that to have a general ability to $\phi$, there have to be some situations in which the agent has the particular ability to $\phi$, is very straightforward. Take the general ability to light a match. To have that ability, there will obviously have to be quite a few situations in which the agent has the particular ability to light a match - in which she intends to light one and succeeds. If there were no such situations, then SUCCESS could not be met for the general ability to light a match to begin with. It is only met, after all, if the pro-

11 Unless, of course, specific abilities are interpreted solidly, i.e. such that they entail the having of a general ability. When I speak of specific abilities, I mean the specific abilities of the nonsolid kind, unless otherwise noted. 
portion of the relevant intention situations in which the agent lights a match is high enough. If there are no intention situations in which the agent intends to light the match and lights it, then this cannot be true. A general ability to $\phi$ therefore entails that the agent also has a particular ability to $\phi$ in at least some situations.

Let me emphasize that those situations - the situations in which the agent has the particular ability to $\phi-$ need not be actual. It is perfectly possible for an agent to have a general ability to light a match without having a particular ability to light a match in any actual situation. One need not ever actually intend to $\phi$ and $\phi$ in order to have a general ability to $\phi$, after all. Perhaps there is always reasons for me not to intend to light a match. Or there is never a match around. All this is perfectly compatible with my having the general ability to light a match.

To what extent can general abilities be thought of as being constituted by particular abilities? Again, the line of reasoning is quite straightforward: we can think of a an ability to $\phi$ as being constituted by the set of the relevant possible situations in which the agent intends to $\phi$ and $\phi$ 's. A particular ability is then constituted by exactly one set of situations - the one relevant possible situation in the modal base in which the agent intends to $\phi$ and does $\phi$. General abilities are correspondingly constituted by the sets of situations in their modal bases in which the agent intends to $\phi$ and $\phi$ 's. Each such situation constitutes a particular ability to $\phi$ in those very circumstances. Hence, general abilities can be seen as being constituted by particular abilities.

\subsubsection{Success and failure}

A very controversial issue in the literature is how specific abilities relate to individual failure and success. In the case of general abilities, it is obvious that such abilities can be retained, even when an actual intention to exercise them is not successfully realized. This can be put in terms of the maskability of general abilities. General abilities can be masked: my ability to swim can be masked by a cramp in my foot, my ability to sing can be masked by my temporary hoarseness, my ability to hit the bull's eye can be masked by me being distracted, and so forth. All of those things prevent my intention from being successfully realized, but they do not deprive me of my general ability. General abilities are not lost in virtue of a singular failure, then.

Reversely, an individual success does not bestow an agent with a general ability. The agent may successfully $\phi$ in a specific situation and yet she may not have a general ability to $\phi$. This has to do with the reliability of general abil- 
ities. To have such an ability, the agent has to be able to perform successfully in a variety of situations. A singular success cannot guarantee any such thing.

The interesting question is how specific abilities relate to failure and success. There are two questions here. First: does an individual success show that the agent had the specific ability to $\phi$ in the situation she was in? And secondly: is the having of a specific ability compatible with failure? Both questions are highly controversial within scholarly discourse.

As to the first question, many think that if an agent $\phi$ 's, then this suffices to show that the agent had the specific ability to $\phi$. Austin, for instance, holds that when a golfer holes a putt, "it follows merely from the premise that he does it, that he has the ability to do it, according to ordinary English" (Austin 1956: 218). Mele (2002) thinks that things are more complicated than that. And Whittle (2010) thinks that there is a sense of "specific ability", which requires that the agent be able to reliably replicate her action under the very same circumstances. I am not quite sure what it would take for a subject to be able to replicate an act under the exact same circumstances, but Whittle clearly commits to the view that a singular success does not suffice for the having of certain kinds of specific abilities. Things are controversial, to say the least.

Likewise for the second question. Does a failure to $\phi$ show that the agent did not have the specific ability to $\phi$ ? Or are specific abilities maskable in the sense that they can be retained even if the agent tries and fails? Here, too, intuitions vary. Fara (2008) is clear on the matter: he thinks specific abilities can be masked. Whittle (Whittle 2010) thinks that some fairly specific abilities can be masked, but that the most specific abilities cannot. A third stance would be the view that if you try and fail, this shows that you lacked the specific ability to $\phi$ (von Wright 1963: 61).

We can note that the connection between specific abilities and success and failure is far from clear. There are quite a few ideas floating around, and thus far, there is little understanding of the way they relate and which of the conflicting ideas captures the primary notion of specific abilities, if there is such a thing. Against the background of the various distinctions we drew between various kinds of specific abilities, however, it should by now be clear that a lot hinges on one's understanding of a specific ability here.

Particular abilities are maximally closely related to failure and success. An agent has a particular ability in a certain situation if and only if she intends to $\phi$ and succeeds. If she intends to $\phi$ and fails, she lacks the particular ability. An individual success therefore bestows, and an individual failure deprives the agent of a particular ability. This entails that particular abilities are not maskable. Whatever it is that prevents the agent from successfully $\phi$-ing goes into the 
modal base. It therefore deprives her of the ability to begin with and does not, as in the case of general abilities, mask it.

Things are more complicated in the case of conative abilities. Here, we vary whether or not the agent intends to $\phi$. Hence, the relevant possible situations will contain some in which the agent intends to $\phi$ and some in which the agent does not intend to $\phi$. The agent has the conative ability if and only if she $\phi$ 's in a sufficient proportion of the relevant intention situations. Whether or not an actual success suffices for the agent to have an ability and whether or not an actual failure suffices for the lack of the ability depends crucially on the standards for what counts as a sufficient proportion. Perhaps the agent has to $\phi$ in all of the relevant intention situations in order to count as having a conative ability in a context. If this is the case, then an actual failure deprives the agent of the ability, but an actual success does not bestow her with it. If the agent has to $\phi$ in one of the relevant intention situations, in contrast, then it is the other way around. If she has to $\phi$ in a few, neither is the case. So here, context will play a crucial role. The same, I take it, goes for opportunities.

\subsubsection{Degrees of specificity}

General and specific abilities differ in the kinds of facts that go into their respective modal bases. In the case of general abilities, we hold only the stable, mostly intrinsic features of the agent fixed. In the case of specific abilities, we also hold various features of the situation fixed. By now we know that the kinds of facts that go into the modal base also vary within the class of general abilities and within the class of specific abilities.

In the case of the general ability to shoot a rabbit, we may hold only the agent's properties underlying the agent's shooting skills fixed or we may additionally hold her moral reservations against shooting animals fixed. In the case of the general ability to juggle, we may want to hold fixed that the agent is currently in a coma, or we may vary this fact and only hold the properties underlying the agent's juggling skills fixed. And so on. Likewise for specific abilities. We may hold the totality of the facts about the agent and her situation fixed, we may vary the agent's motivational states, we may vary certain facts about the external situation, or vary both some motivational states and some external facts.

Intuitively, this seems to indicate that abilities form some sort of scale, along which various abilities to $\phi$ can be ordered in accordance with their specificity and generality, respectively. The more facts are held fixed, the more specific is an ability. The less facts are held fixed, the more general. Or so it seems. 
Actually, things are a bit more complicated. As I will argue, there is indeed sense to be made of an ordering of abilities according to their degree of specificity, but first of all, that ordering will only be partial (not any two abilities to $\phi$ stand in the "is more specific than" relation to one another), and secondly, the sheer number of facts that are held fixed across situations is not the proper criterion for the ordering. Let me take these points in reverse order.

Seeing that the number of facts is not the crucial criterion for specificity is easy. It is, for instance, not at all clear why my ability to do a handstand with a broken arm (one fact?) should be less specific than my ability to do a handstand on a stage while being drunk (two facts?). The sets of facts that are held constant in both cases are simply different. It is not reasonable to think that their sheer number has anything to do with the ability's specificity.

Yet, some abilities do seem to be more specific than others. My ability to sing on stage when Adele sits in the audience seems to be more specific than my ability to sing on stage, for instance. What seems to matter, then, is that the facts that are held constant are properly related. In which way? One idea would be to say that

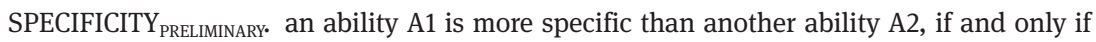
the set of facts held fixed in the case of $\mathrm{A} 2$ is a proper subset of the set of facts held fixed in the case of A1. If A1 is more specific than $\mathrm{A} 2$, then $\mathrm{A} 2$ is more general than A1.

This yields the right results in the cases we looked at. My ability to do a handstand with a broken arm does not come out more specific than my ability to do a handstand on stage while being drunk, whereas my ability to sing on stage when Adele is present does come out more specific than my ability to sing on stage.

But we need to take one further subtlety into account. I take it that we want to be able to say that your ability to sing on stage when Adele is present is more specific than my ability to sing on stage. And this does not follow, if the facts we are holding constant in my case have to be a proper subsets of the facts we are holding fixed in your case. We will, among other things, hold your larynx system fixed in your case while holding my larynx system fixed in my case, after all.

This suggests that it is not actually the facts themselves which have to be related in the right way in order to yield degrees of specificity, but kinds of facts. What we are holding fixed are facts about the agent's larynx system. That means we are holding facts about you fixed in your case and facts about me in my case. This suggests that 
SPECIFICITY. an ability A1 is more specific than another ability A2 if and only if the kinds of facts that are held fixed in the case of $\mathrm{A} 2$ are a proper subset of the kinds of facts that are held fixed in the case of A1. If A1 is more specific than A2 then $\mathrm{A} 2$ is more general than $\mathrm{A} 1$.

It should by now be clear why we will not end up with a full linear ordering of abilities to $\phi$. It is simply not the case that any two abilities to $\phi$ will stand in the "is more specific than" relation to one another, if specificity is spelled out in the way I just proposed. The ability to do a handstand with a broken arm and the ability to do a handstand on stage while being drunk, for instance, are clear examples of abilities that do not match up neatly with respect to their respective degrees of specificity.

\subsubsection{Hypothetical circumstances}

There is one rather intricate issue we have to turn to before closing the section on general and specific abilities: we need to turn to the role of hypothetical circumstances. To see what I am getting at, take the ability to do a handstand with a broken arm as opposed to the ability to do a handstand. On the account of general and specific abilities I have just given, the former is more specific than the latter. In the case of the former, we hold the agent's broken arm fixed; in the case of the fully general ability, we don't.

Now let's suppose the agent does not actually have a broken arm. Then we obviously cannot think of the broken arm as something we hold fixed. What we hold fixed, across possible situations, are always features of the actual situation. Hence, the distinction between the ability to do a handstand and the ability to do a handstand with a broken arm cannot, in such a case, be captured in terms of a difference in the facts we hold fixed, with the broken arm being among the fixed facts in one case but not in the other. And that means that the account of degrees of specificity cannot be applied to the distinction between the ability to do a handstand and the ability to do a handstand with a broken arm.

This points to a more general issue. Earlier, we saw that, according to Kratzer, the modal base of an ability is always realistic. We hold certain facts of the actual situation fixed across the possible situations, and hence the actual world will always be contained in the situations which make up the modal base. This is just as it should be: as Kratzer so insightfully taught us, agents have abilities in view of certain facts. The modal base is the set of situations in which those facts are held constant - it is the set of situations in which the facts obtain in view of which an agent has or lacks an ability. 
What the example of the broken arm shows, however, is that hypothetical circumstances - circumstances that are not facts, but non-actual states of affairs - play a vital role in our thinking about abilities as well. We may be interested in an agent's ability to do a handstand with a broken arm, no matter whether or not the agent actually has a broken arm. We may be interested in an agent's ability to run a marathon in hot weather, no matter whether the runner is actually located in Sumatra or at the North Pole. And we may be interested in an agent's ability to jump on one foot when completely drunk, even if the agent has never had a sip of alcohol. Hypothetical circumstances enter into our thinking about abilities quite often, then. The question I will pursue in this section is: how do they enter?

The answer is a bit complicated, because hypothetical circumstances can enter in a variety of ways. So far, we have thought about the role of circumstances only in terms of the facts about the agent and her situation that are held fixed across the possible situations - the sets of circumstances in view of which the agent has the ability. That is to say that the structure of ability statements, as we have thought of it so far, looked like this:

CAN. S can, in view of $\mathrm{C}^{\star}, \phi$.

$C^{\star}$ is the set of circumstances in view of which the agent has the ability. That set of circumstances is always factual: only facts - states of affairs which obtain at the actual world - can go into $C^{\star}$. Since $C^{\star}$ determines the modal base of an ability, the modal base of abilities is always realistic: the actual situation is always among the modal base situations.

In fact, however, the structure of abilities is way more complex. As I will lay out in what follows, ability statements have four, instead of just one, placeholders for circumstances. Really, they have the following structure:

$\mathrm{CAN}^{\star}$. In $\mathrm{C} 1, \mathrm{~S}$ can, in view of $\mathrm{C}^{\star}$ and when $\mathrm{C} 3, \phi$-in-C2.

As before, $\mathrm{C}^{\star}$ is the set of circumstances in view of which the agent has the ability. This set of circumstances is factual. It determines a realistic modal base. C1, C2, and C3 are further sets of circumstances. Importantly, all of those circumstances can be purely hypothetical. To see what I am getting at, let's look at an example of an ability ascription which features hypothetical circumstances and see how it can be interpreted. Let's assume that Fred is actually in a place with cold weather. On this assumption, let's see how we can interpret a statement like the following: 
(A) Fred can, in view of his physical constitution $\left(\mathrm{C}^{\star}\right)$, run a marathon in hot weather.

As I will argue, there are three distinct interpretations available, depending on whether the hypothetical circumstances - Fred being in hot weather - enter the ability ascription via $\mathrm{C} 1, \mathrm{C} 2$ or $\mathrm{C} 3$. Here is the first interpretation:

(INT-1) In hot weather (C1), Fred has, in view of his physical constitution $\left(\mathrm{C}^{\star}\right)$, the ability to run a marathon.

In INT-1, the hypothetical circumstances are outside the scope of the ability ascription. What is stated is that Fred has a certain ability under certain circumstances. A statement of this form does not imply that the agent actually has the ability to run a marathon. It is a statement about an ability that is had under certain conditions, and it entails a statement about the agent's abilities in actuality only if the conditions specified in $\mathrm{C} 1$ are actual and not merely hypothetical.

The statement can therefore also be interpreted in the subjunctive mode. It can be read as the statement that if the weather were hot, Fred would (in view of his physical constitution) have the ability to run a marathon. If we translate this into the framework of the success view, INT-1 states the following:

(INT- SUCCESS $_{\text {S }}$ If Fred were in hot weather (C1), then Fred would run a marathon in a sufficient proportion of the possible situations in which Fred has his actual physical constitution $\left(\mathrm{C}^{\star}\right)$ and intends to run a marathon.

The hypothetical circumstances give a condition for the having of an ability, which is itself structured as before. Within the scope of the ability operator, hypothetical circumstances play no role.

For the second interpretation, let's assume that the hypothetical circumstances enter the ability ascription via C2. That is to say: they enter the ability ascription in the form of a specification of the action type the agent is said to be able to perform - in a statement of the form "S can $\phi$ ", they qualify " $\phi$ ". If we interpret the statement along those lines, it states the following:

(INT-2) Fred has, in view of his physical constitution $\left(C^{\star}\right)$, the ability to run-a-marathon-inhot-weather (C2).

The hyphens indicate an action type: running-a-marathon-in-hot-weather is a different action type from just running a marathon. The hypothetical circumstances do the same job as any other action type qualifier: running-in-hot-weather functions like running slowly, running on one leg, or running in circles. In con- 
trast to the first interpretation, the second interpretation does entail that the agent actually has the ability in question. It states that Fred has, in view of his physical constitution, the ability to perform a certain action type, namely running-a-marathon-in-hot-weather.

How is INT-2 accommodated by the success view? According to the success view, S has an ability to $\phi$ if and only if the agent $\phi$ 's in a sufficiently high proportion of relevant possible situations in which the agent intends to $\phi$. Since $\phi$ ing corresponds to running-a-marathon-in-hot-weather in INT-2, INT-2 therefore states the following:

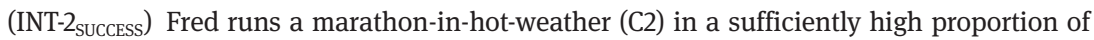
the possible situations in which Fred agent has his actual physical constitution $\left(\mathrm{C}^{\star}\right)$ and intends to run-a-marathon-in-hot-weather (C2).

Running-a-marathon-in-hot-weather is treated just like any other qualified action type, then. An agent has the ability to run on one leg, according to the success view if and only if the agent runs on one leg in a sufficient proportion of relevant possible situations in which the agent intends to run on one leg. Running-a-marathon-in-hot-weather is accommodated in the very same way.

Finally, let's turn to the third interpretation: here, we want to express that Fred has, in view of his physical constitution, the ability to perform the action type of running a marathon when certain hypothetical circumstances obtain namely, when the weather is hot. We are stating the following, then:

(INT-3) Fred has, in view of his physical constitution ( $\left.\mathrm{C}^{\star}\right)$ and when the weather is hot (C3), the ability to run a marathon.

That this makes sense and is an important way of interpreting the ability statement in question (and ability statements containing hypothetical circumstances quite generally) becomes most apparent when we think of contexts in which two agents' abilities to perform one and the same action type are compared. Suppose I say, bracketed terms being implicit: "Frieda can (in view of her physical constitution) run a marathon". And you say "Yeah, but Fred can (in view of his physical constitution) run a marathon even in hot weather”. Then it seems to me that, intuitively, the best way to make sense of this conversation is in terms of the third interpretation I have suggested.

Your statement is definitely not intended to state, along the lines of the first interpretation, that there are certain hypothetical circumstances in which Fred has one and the same ability that Frieda has in actuality. You seem to be committing to Fred having an ability in actuality as well, namely the ability to run a marathon under certain hypothetical circumstances. 
Likewise, I believe, it is also not very useful to think of your statement as saying that Fred has the ability to perform a rather different action type than Frieda. Rather, what you seem to be saying is that Fred can perform one and the same action type as Frieda, but he can do so under more conditions while Fred can run a marathon in situations in which the weather is hot, Frieda cannot.

How can the third interpretation be accommodated by the success view? My suggestion is that INT-3 should be understood along the following lines:

(INT-3 $3_{\text {SUCCESS }}$ ) Fred runs a marathon in a sufficiently high proportion of the possible situations in which (i) his physical constitution is as in actuality ( $\left.C^{\star}\right)$, (ii) he is in hot weather (C3), and (iii) he intends to run a marathon.

On this interpretation, the hypothetical circumstances impose a further restriction on the situations among which we check for intention situations, among which, in turn, we check for performance cases. We first restrict the possible situations to the ones in which the relevant facts obtain, yielding a realistic modal base with the actual situation in it. But then we impose a second restriction. We restrict the situations further to the ones in which certain hypothetical circumstances obtain. In this step, the actual situation gets kicked out.

INT-3 yields a modification of some of the things I have about the set of relevant possible situations. So far, I have identified the relevant possible situations with the situations in which the facts obtain in view of which an agent has an ability. When hypothetical circumstances enter an ability statement via C3, however, the relevant possible situations will in fact be a subset of those situations: those in which those hypothetical circumstances obtain as well.

Quite often, hypothetical circumstances do not play a role. We may, after all, simply be interested in an agent's ability to do things in the very circumstances she is actually in. We may be interested in an agent's ability to run a marathon in hot weather when the agent is actually in hot weather. In such cases, our thinking about what an agent can do is simply a thinking about what the agent can do in view of certain intrinsic or extrinsic features of hers - being in hot weather, say.

But, and this is where hypothetical circumstances become relevant, we may also be interested in an agent's ability to run a marathon in hot weather when the agent is actually in a cold environment. In that case, the restriction to hot weather situations has nothing to do with the features in view of which the agent has the ability. The hypothetical circumstances come into play from the outside, so to speak. The relevant possible situations are a subset of the relevant 
possible situations in which facts of the actual situation are held fixed in that case.

What I contend, then, is that ability statements will sometimes have to be read as statements of the form "In view of $\mathrm{C}^{\star}$ and when $\mathrm{C} 3, \mathrm{~S}$ can $\phi$ ", where C3 specifies a contextually determined set of circumstances, which may well be hypothetical. When we ask whether some agent has the ability to run a marathon in hot weather, we will always have to restrict the realm of possible situations to the ones in which the weather is hot. But for the agent in Sumatra, that comes down to a restriction to situations that are similar to hers with respect to the weather conditions, whereas for the agent at the North Pole it amounts to a restriction to situations that differ from hers with respect to that feature.

Let us take stock. What I have laid out in the last paragraphs are three ways in which hypothetical circumstances can enter ability ascriptions. Depending on how they enter, we get different interpretations of an ability statement with a reference to hypothetical circumstances: that a certain ability is had under certain hypothetical circumstances (INT-1); that the agent has an ability to perform some-action-in-certain-hypothetical-circumstances (INT-2); or that the agent has an ability to perform some action when certain hypothetical circumstances obtain (INT-3). Each of those interpretations is accommodated differently by the success view.

What does all this have to do with general and specific abilities? I have said, in the last section, that

SPECIFICITY. an ability A1 is more specific than another ability A2, if and only if the kinds of facts that are held fixed in the case of A2 are a proper subset of the kinds of facts held fixed in the case of A1. If A1 is more specific than A2, then A2 is more general than A1.

Since specificity is formulated in terms of facts that are held fixed, the definition does not accommodate cases in which hypothetical circumstances play a role. This may strike you as mislead. The ability to run a marathon in hot weather, you may think, is obviously more specific than the ability to run a marathon, no matter whether or not the agent is actually in hot weather. The suggestion would then be that specificity can come about via any of the sets of circumstances which can figure in an ability ascription. Specificity via the actual facts we hold fixed would turn out to be but one way among many in which specificity can come about, according to that account.

Basically, I think this is exactly right. Yet, I will reserve the terms "specific" and "general" for ways in which different sets of actual circumstances can relate within ability ascription, as spelled out in SPECIFICITY. In the remainder of this 
section, I will give some definitions for the various similar relations - relations between further sets of circumstances, C1, C2, and C3, that can figure in ability ascriptions. For reasons of taxonomical clarity, each of these relations will be dubbed differently. Besides specificity, abilities can differ in their dependency, complexity, completeness, determinacy, and locality.

First, dependency. Let us say that

DEPENDENCY. an ability A1 is more dependent than an ability A2 if and only if the kinds of circumstances under which $\mathrm{A} 2$ is had are a proper subset of the kinds of circumstances under which $\mathrm{A} 1$ is had. If $\mathrm{A} 1$ is more dependent than $\mathrm{A} 2$, then $\mathrm{A} 2$ is more independent than $\mathrm{A} 1$.

Dependency comes about when varyingly inclusive sets of circumstances enter an ability ascription via C1. The more inclusive the set of circumstances on which the having of an ability depends, the higher the degree of dependency. DEPENDENCY thus yields that "In hot weather and with a broken leg, S has the ability to run a marathon" ascribes a more dependent ability than "In hot weather, S has the ability to run a marathon".

Further, let us say that

COMPLEXITY. an ability A1 is more complex than an ability A2 if and only if the kinds of circumstances that go into the action description in the case of A2 are a proper subset of the kinds of circumstances that go into the action description in the case of A1. If A1 is more complex than A2, then A2 is more simple than A1.

Complexity comes about when varyingly inclusive sets of circumstances enter an ability ascription via $\mathrm{C} 2$. The more inclusive the set of circumstances that determine the action type of the ability ascription, the more complex the ability. COMPLEXITY thus yields that " $S$ has the ability to run a marathon-in-hot-weatherand-with-a-broken-leg" ascribes a more complex ability than "S has the ability to run-a-marathon-in-hot-weather".

Further, let us say that

DETERMINACY. an ability A1 is more determinate than an ability A2 if and only if the kinds of hypothetical circumstances that (partly) determine the relevant possible situations in the case of A2 are a proper subset of the kinds of hypothetical circumstances that (partly) determine the relevant possible situations in the case of $\mathrm{A} 1$. If $\mathrm{A} 1$ is more determinate than $\mathrm{A} 2$, then $\mathrm{A} 2$ is more indeterminate than $\mathrm{A} 1$. 
Determinacy comes about when varyingly inclusive sets of circumstances enter an ability ascription via C3. The more inclusive the set of kinds of hypothetical circumstances that partly determine the relevant possible situations, the higher the degree of completeness. DETERMINACY thus yields that " $\mathrm{S}$ has the ability to run a marathon when the weather is hot and S has a broken leg" ascribes a more determinate ability than " $S$ has the ability to run a marathon when the weather is hot". Since the circumstances that enter via C3 combine with the facts that are held fixed in an ability ascription $\left(\mathrm{C}^{\star}\right)$ to determine the relevant possible situations, a higher degree of determinacy will, ceteris paribus, yield a more exclusive set of relevant possible situations.

Finally, the relevant possible situations as a whole may be more exclusive in the case of one ability than in the case of another. I will speak of locality in that case. Let us say that

LOCALITY. an ability A1 is more local than an ability A2 if and only if the circumstances, actual and hypothetical, that determine the relevant possible situations in the case of A2 are a proper subset of the circumstances, actual and hypothetical, that determine the relevant possible situations in the case of A1. If A1 is more local than A2, then A2 is more global than A1.

\subsection{Masks}

So far, we have seen that the success view delivers an account of degrees of abilities as well as of general and specific abilities and that it circumvents the problem of the impeded intention. In this section, I will argue that it also circumvents the problem of masks, as it emerged in connection with the simple conditional analysis.

According to the simple conditional analysis, an agent has an ability to $\phi$ if and only if the agent would $\phi$, if she intended to. For the simple conditional analysis, the problem with masks is that there are cases in which an agent has the ability to perform some action, and yet it is not true that the agent would perform the action if she intended to perform it. In fact, it can pretty much always be the case that the world is such that something would interfere with the exercise of the intended performance. A sudden gust of wind can blow the golf ball off course and prevent the able agent from holing the putt. A broken leg can prevent the swimming champion from actually swimming. And a cramp in a gymnast's arm can prevent her from doing the handstand she has so often done before.

The problem has to do with the truth conditions of the counterfactual. A counterfactual is true if and only if the closest worlds in which the agent intends 
are worlds in which she succeeds. ${ }^{12}$ That means that we must depart from the actual world no further than necessary to reach an intention world. That is a problem. If the actual world happens to contain an interfering factor for the exercise of an intention on the agent's part, then this interfering factor will in all likelihood also be present in the closest worlds in which the agent intends to $\phi$. Hence, the agent's intention will not be realized in that world.

Having said this, it should already have become apparent why the same problem does not arise for the success view. The success view does not just take situations into account which are, apart from the fact that the agent intends to $\phi$ in them, as similar to the actual situation as possible. Rather, most facts of the actual situation are completely irrelevant to the determination of the set of situations that matters to the agent's ability. When we are thinking about the golfer's ability to hole a putt, we are usually not interested in the ability to hole a putt in view of the actual wind regime. Hence, the wind regime is not held constant across possible situations.

What is held constant? That depends. The agent's bodily and mental constitution could be one set of features. If we then ask whether the agent holes the putt in a sufficient proportion of situations in which those circumstances obtain and she intends to hole it, the answer may well be "yes". This is so despite the fact that the actual situation is one in which the agent's intention would not have been successfully realized.

Masks are not a problem for the success view, then, because the mask - the interfering factor in the actual situation - is usually varied across the relevant possible situations. That means that the very few situations in which the mask is present do not in any sense have priority over situations in which it is not present. Hence, the fact that the actual situation is a mask situation is not of particular interest. The actual situation does not have any special status among the realm of the relevant possible situations.

It is worth noting that a feature that is a mask for one ability may well be a circumstance that deprives the agent of another, more specific ability (no matter whether the higher specificity is achieved in terms of locality or more determinateness). The wind regime, for instance, is a mask for the golfer's general ability to hole a putt, but it really deprives her of her ability to hole a putt in view of the actual wind regime. The agent has the former ability but lacks the latter. The reason for her lack of the latter is that we have hold a feature fixed that is merely a mask for the former ability and therefore gets varied in that case.

12 Again, I neglect problems with the limit assumption. 
For another example, compare the ability to do a handstand and the ability to do a handstand with a broken arm. In the case of the ability to do a handstand, broken arms usually get varied. In the case of the ability to do a handstand with a broken arm, in contrast, they are held constant. Again, the agent has the former ability, but lacks the latter. The reason for that is that the feature that figures as a mask for the former ability gets fixed in the case of the latter ability. The agent does a handstand in a sufficient proportion of the possible situations in which she intends to do a handstand and her muscular constitution, say, is as in actuality. But she does not do a handstand in a sufficient proportion of the possible situations in which she intends to do a handstand and her arm is broken.

\subsection{Formal considerations revisited}

This chapter is about to draw to a close. What remains to be discussed before we move on is the impact of the last objection we looked at in chapter 3, in our discussion of possibilism. As Kenny has convincingly shown, possibilism is bound to fail in virtue of the fact that the ability operator - the "can" of ability - does not obey even the most basic laws governing possibility. This section explores whether or not the same or a related objection arises for the success view as well.

Kenny's argument against possibilism, recall, goes like this. The focus is on two modal axioms, T and K2, the first of which holds for most, and the second for any possibility operator:

T. $\mathrm{p} \rightarrow \diamond(\mathrm{p})$

K2. $\diamond(p \vee q) \rightarrow(\diamond(p) v \diamond(q))$

As Kenny shows, both T and K2 fail to state laws when $\diamond$ is interpreted as the ability operator. From this he concludes that the "can" of ability cannot be interpreted in terms of restricted possibility.

I take it to be obvious that the argument, as it stands, does not affect the success view. The success view does not interpret abilities in terms of restricted possibility. Hence, it is not to be expected that the "can" of ability obeys the same laws as the possibility operator. Hence, to make the reverse point, a failure to meet the basic laws of possibility does not pose a problem for the success view.

That SUCCESS ${ }_{\mathrm{AA}}$ analyzes CAN, the "can" of ability, as something other than restricted possibility should be obvious, but let me make the differences explicit once more. According to the success view, 
SUCCESS $_{\mathrm{AA}}$. an agent $\mathrm{S}$ has an ability to $\phi$ if and only if $\mathrm{S} \phi$ 's in a sufficient proportion of relevant possible situations in which $S$ intends to $\phi$.

Compare this condition to the truth conditions for possibility statements:

$\diamond$. It is possible that $\mathrm{p}$ if and only if there is at least one $\mathrm{p}$ world among the relevant worlds.

Apart from the fact that SUCCESS $_{\mathrm{AA}}$ is formulated in terms of situations instead of complete worlds, there are two important differences between those two conditions. First, SUCCESS ${ }_{\mathrm{AA}}$ imposes a second restriction on the realm of the possible situations. The possible situations get restricted not only to the relevant ones, but rather to the relevant ones in which the agent intends to $\phi$. Secondly, and more importantly, while $\diamond$ requires only that there be at least one p-world among the restricted set of worlds, SUCCESS requires that there be a sufficient proportion of performance cases among the restricted set of situations.

These differences are crucial - ability ascriptions behave very differently from possibility ascriptions. For that reason, it is not to be expected that they obey the modal laws governing possibility - no matter how basic those laws are in that realm.

Interestingly, Kenny seems to think that his argument shows that any possible worlds analysis of ability is bound to fail (1976: 226). But this strikes me as a clear non sequitur from the insight that abilities cannot be understood as restricted possibilities. For the inference to go through, the only available possible worlds analysis of abilities would have to be one in terms of possibility. Clearly, this assumption is misled, if the success view is on the right track. Kenny's objection from formal inadequacy does not affect the success view.

But wait a minute, you may say. So possibilism fails because it analyzes abilities as restricted possibilities and is therefore committed to the validity of certain modal inferences, which fail to hold for ability statements. And the reason this does not affect the success view is that the success view does not analyze abilities in terms of restricted possibilities and is therefore not committed to the validity of the same inferences. But isn't this, too, a non sequitur?

Agreed. Even though the success view does not explicitly analyze abilities in terms of restricted possibilities, SUCCESS ${ }_{\mathrm{AA}}$ may still turn out to entail the very same inference rules Kenny has shown to be invalid for ability statements. In that case, Kenny's argument would be easily adaptable as a refutation of the success view. For then we could easily argue:

i. If SUCCESS $S_{\mathrm{AA}}$ is true, then T and K2 should generally hold for CAN (because T and K2 are implied by SUCCESS $_{\mathrm{AA}}$ ) 

ii. T and K2 do not generally hold for CAN.
iii. Hence, SUCCESS $_{\mathrm{AA}}$ is false.

In the remainder of this section, I am going to show that (i) is false. ${ }^{13}$ Let "CAN" once more stand for the "can" of ability, and let it function as a sentences operator with scope over a proposition. Adapting T and K2 for CAN, we get the following two principles:

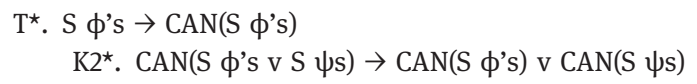

Both, we know, fail to state laws. SUCCESS ${ }_{\mathrm{AA}}$ is perfectly in line with that. In fact, the truth of SUCCESS $\mathrm{AA}_{\mathrm{AA}}$ explains why $\mathrm{T}^{\star}$ and $\mathrm{K}^{\star}$ fail to state laws.

On the one hand, it is not generally true, according to SUCCESS $_{\mathrm{AA}}$, that if $S$ $\phi$ 's, $S$ has the ability to $\phi$. That is because it is not generally true that if $S \phi$ 's, then $S$ 's in a sufficient proportion of the relevant possible situations in which S intends to $\phi$. Take the general ability to hit the bull's eye and suppose all we hold fixed is the agent's amount of training (plus some background assumptions). Then obviously, the mere fact that I hit the bull's eye in actuality does not prove that I hit the bull's eye in a sufficient proportion of relevant possible situations in which I intend to hit it. It may clearly be the case that I fail miserably in almost all of the other situations in which I have had the same amount of training. In a nutshell: SUCCESS does not entail the general truth of $\mathrm{T}^{\star}$, because SUCCESS yields that $\mathrm{T}^{\star}$ fails whenever "ability" is given a less than maximally specific interpretation.

SUCCESS $_{\mathrm{AA}}$ does not entail the general truth of $\mathrm{K} 2$, either. By inserting the truth conditions SUCCESS ${ }_{\mathrm{AA}}$ postulates for ability statements into K2, we get:

$\mathrm{K} 2^{\star}$. If S $\phi$ 's or $\psi$ 's in a sufficient proportion of the relevant possible situations in which S intends to $\phi$ or $\psi$, then S $\phi$ 's in a sufficient proportion of the relevant possible situations in which S intends to $\phi$, or S $\psi$ 's in a sufficient proportion of the relevant possible situations in which $\mathrm{S}$ intends to $\psi$.

This is not a valid principle either. It is, for instance, true that I draw a red card or a black card in a sufficient proportion of the relevant possible situations in which I intend to draw a red card or a black card. Actually, the proportion of

13 Refuting (i) does not suffice to show, of course, that SUCCESS ${ }_{\mathrm{AA}}$ does not falsely entail the validity of any other invalid inferences. Since I cannot show, for any invalid inference, that SUCCESS does not entail its validity, however, I assume that refuting (i) is all that is required at this point. 
such situations is presumably extremely high - there is not much that could stop me from realizing that kind of intention when faced with a stack of cards. It is not true, in contrast, that I draw a red card in a sufficient proportion of relevant possible situations in which I intend to draw a red card. My intention to draw red is not as closely linked to a successful performance. In fact, it will be no higher than 50\% - mere luck, given that there are only two colors available.

We can conclude that Kenny's counterexamples against possibilism do not spell any kind of trouble for the success view. On the one hand, the success view does not postulate that abilities are some kind of restricted possibilities. It is therefore not per se committed to the claim that the ability operator obeys the basic laws for possibility. On the other hand, there is no reason to assume that the success view is otherwise committed to the problematic principles. Instead, as I have shown, the truth conditions for ability statements given by SUC$\mathrm{CESS}_{\mathrm{AA}}$ account for the counterexamples against $\mathrm{T}^{\star}$ and $\mathrm{K} 2^{\star}$ perfectly. If SUCCES$\mathrm{S}_{\mathrm{AA}}$ is true, then it rightly follows that $\mathrm{T}^{\star}$ and $\mathrm{K} 2^{\star}$ are not generally true.

\subsection{Finks and other unintentional abilities}

In the last five sections, we saw that the success view is extremely powerful in that it accounts for all of the adequacy conditions for a comprehensive view of (agentive) abilities and does not run into the problems that proved destructive for the simple conditional analysis and possibilism. In this and the next section, I will discuss an objection to the success view that comes to mind quite easily. As it seems, there are cases in which an agent has an ability to $\phi$, but can only exercise it if she does not intend to $\phi$. Call abilities of that kind "unintentional abilities". In response to this objection, I will formulate a weaker version of the success view, according to which having an unintentional ability is for the agent to $\phi$ in a sufficient proportion of the relevant possible situations in which the agent intends to $\psi$, where " $\psi$ " specifies a different action type than “ $\phi$ ”, but $\phi$-ing in response to intending to $\psi$ counts as a success.

According to the success view, an agent has an agentive ability to $\phi$ if and only if the agent $\phi$ 's in a sufficient proportion of relevant possible situations in which the agent intends to $\phi$. But can we not easily think of cases in which an agent has an agentive ability, but can only exercise it if she does not intend to? In such cases, the success view yields wrong results. The modal success rate - the proportion of performance situations among the relevant intention situations - will be zero. The success view will therefore falsely predict that the agent lacks the ability in such cases. 
The reader familiar with the debate on dispositions will presumably immediately think of cases that exhibit a similar structure: cases of finkish dispositions. Call a disposition finkish if and only if the occurrence of the stimulus interferes with the manifestation. ${ }^{14}$ Many examples of finkish dispositions are quite far out - sorcerers and magic often play a crucial role (Lewis 1997); but in fact, we are surrounded by finkish dispositions in everyday life. An ordinary fuse, for instance, is a fink for a wire's disposition to conduct electricity when touched by a conductor (Molnar 1999). The wire has that disposition, but once it is attached to a fuse, touching the wire will make it go dead. Like in masking cases, the object will therefore not show the manifestation when the stimulus occurs. The reason, however, is not that something external interferes with the manifestation after the stimulus occurs (as in the case of masks), but rather that that the stimulus itself interferes with the manifestation.

Can we think of similar cases in the sphere of abilities? Let's call an ability finkish if and only if the intention itself interferes with the successful exercise of the ability. At first, it seems easy to think of abilities which meet this characterization. Some abilities wear their finkishness on their sleeves. Think of the ability to unintentionally read street signs; ${ }^{15}$ or the ability to follow a conversation at another table without listening. Abilities of this kind can only be exercised when the agent does not intend to exercise them. That seems to be a problem for the success view. According to the success view, an agent has an ability to $\phi$ only if the agent $\phi$ 's in a sufficient proportion of relevant possible situations in which the agent intends to $\phi$. In cases in which the agent's intention interferes with her $\phi$-ing, this condition will never be met. Hence, the success view seems to be unable to account for agents' finkish abilities.

We have to be careful here, though. The examples I just gave for finkish abilities are not very auspicious. The success view, as it stands, is an account of abilities to perform actions, recall. But reading street signs unintentionally and following a conversation at another table without listening are not actions. Rather, they are what I called "mere behaviors" $(\rightarrow 1.4)$. Abilities to perform mere behaviors are what I called non-agentive abilities. Abilities of that kind are not properly captured in terms of a tie between intentions and performance. They call for a slightly different analysis. I will turn to non-agentive abilities in the next chapter.

14 In the case of finkish dispositions, the stimulus interferes with the manifestation by making the disposition itself vanish (Lewis 1997). I am using the term "finkish" more liberally here.

15 I owe this example to David Löwenstein. 
Can we think of finkish agentive abilities? Differently put: are there actions which the agent has the ability to perform, but yet the intention to perform those very actions interferes with the successful performance? I think we can. Here are a few examples:

CASUAL. Frieda has the ability to walk casually, but as soon as she intends to walk casually, she is so self-conscious that her walk becomes stiff and unnatural. Thus, it is not the case that she walks casually in a sufficient proportion of relevant possible situations in which she intends to walk causally.

IN TUNE. Fred has the ability to sing in tune, but as soon as he intends to sing in tune, he becomes so strained that he inevitably sings out of tune. Thus, it is not the case that he sings in tune in a sufficient proportion of relevant possible situations in which he intends to sing in tune.

WITTY. Emma has the ability to make witty and hilarious remarks in talks, but whenever she intends to make witty and hilarious remarks, she overdoes it and tends to create awkward situations. Thus, it is not the case that she makes witty and hilarious remarks in a sufficient proportion of relevant possible situations in which she intends to make witty and hilarious remarks.

The structure of these cases is as follows. There is something an agent has an ability to do, but the intention to do the very thing gives rise to some kind of impediment to actually doing the thing in question. Frieda becomes self-conscious, Fred becomes strained, Emma overdoes the joking. The intention itself results in an impediment to successful performance. What the agents are able to do are obviously actions: walking casually, singing in tune, and making witty and hilarious remarks. Hence, they are not excluded by the explicit restriction of SUCCES$\mathrm{S}_{\mathrm{AA}}$ to agentive abilities.

Apparently, then, there are agentive abilities to $\phi$ which do not require the agent's performances of $\phi$-ing to be appropriately tied to the intention to $\phi$. Sometimes, agents have an ability to $\phi$ and yet fail miserably in situations in which they intend to do the thing in question. I think this is just the way things stand. The cases do indeed pose counterexamples to the success view as I have formulated it. In finkish cases, there will not be a sufficient proportion of performance cases among the relevant intention situations.

It is worth noting that finkish abilities are only a special case of a much broader range of counterexamples to the success view as it stands. In the finkish case, the intention itself interferes with the successful performance of $\phi$-ing. But this need not be so. To come up with counterexamples to SUCCESS, there may just as well be an impediment to the agent's successful performance of $\phi$-ing upon intending to $\phi$, which is completely independent from the agent's forming the intention to $\phi$ itself. Here are two cases of that kind: 
HANDSTAND. When Ela intends to do a handstand against a wall, she always fails, because she doesn't have the slightest idea of how to do it. But when she intends to put her hands on the ground, throw up her legs and hit her feet through the wall, she ends up doing a perfect handstand..$^{16}$

POUR ÉLISE. Peter has the ability to play "Pour Élise" without any mistakes. A forteriori, he has the ability to play the middle part of "Pour Élise" without any mistakes. However, he never succeeds in playing the middle part without mistakes upon intending to. He can only play the piece, and thus the middle part, flawlessly in one go - start to finish. ${ }^{17}$

In both cases, the agent has an ability to perform an action, yet the agent does not exhibit the modal tie between intentions and performances postulated by SUCCESS $_{\mathrm{AA}}$. It is not the case that there is a sufficient proportion of $\phi$-ing situations among the relevant possible situations in which the agent intends to $\phi$. Yet, the reason for the agents' respective failures to meet SUCCESS ${ }_{\mathrm{AA}}$ has to do with impediments that are fully independent from the forming of the intention to $\phi$ itself. In HANDSTAND, the problem is that Ela does not know enough about the proper method of doing a handstand. In POUR ÉLISE, the problem is that whatever program in Peter's brain underlies his piano playing ability, this program can only run through the whole piece flawlessly, but not through parts. In neither case does the intention to $\phi$ itself cause the trouble.

Finkish abilities are a special instance of a whole range of cases in which an agent has an ability which can only be exercised as long as the agent does not intend to exercise it, then. Let us call such abilities "unintentional abilities". Unintentional abilities obviously pose a problem for the success view.

Luckily, unintentional abilities can be dealt with. Despite their obvious impact on the success view, unintentional abilities merely show that the view has to be extended a bit. Thus far, the success view says that for an agent to have an ability to $\phi$, the agent has to $\phi$ in a sufficient proportion of relevant possible situations in which she intends to $\phi$. That is obviously not the case in the examples above. The agent's $\phi$-ing is not appropriately tied to her intention to $\phi$.

There is, however, a different intention to which each agent's performance of $\phi$-ing is appropriately tied, even in the case of unintentional abilities. In the finkish cases, Frieda walks casually in a sufficient proportion of the relevant possible situations in which she intends to walk, for instance. Fred sings in tune in a sufficient proportion of the relevant possible situations in which he intends to sing. Emma make witty and hilarious remarks in a sufficient proportion of the relevant possible situations in which she intends to make remarks.

16 The case has been brought to my attention by Wolfgang Schwarz (personal conversation). 17 The case has been brought to my attention by Barbara Vetter (personal conversation). 
In the non-finkish cases, the same structure can be observed. Ela does a handstand in a sufficient proportion of the relevant possible situations in which she intends to hit her feet against the wall. Peter plays the middle part of "Pour Élise" flawlessly in a sufficient proportion of the relevant possible situations in which he intends to play "Pour Élise".

This suggests the following modification of the success view. On a more liberal understanding of the modal tie between intentions and performances that is required for an agent to have an ability to $\phi$,

SUCCESS $_{\mathrm{AA}}{ }^{*}$. an agent $\mathrm{S}$ has an agentive ability to $\phi$ if and only if there is some intention $\psi$, such that $S$ 's in a sufficient proportion of similar situations in which she intends to $\psi$, where $\phi$ and $\psi$ need not specify the same action type.

This formulation is more liberal than the original formulation in that the intention to which the agent's performances of $\phi$-ing have to be modally tied can (and as a rule, will be), but need not, be the intention to $\phi$ itself. It may well be some other intention.

Is the modification ad hoc? It is not. Instead, SUCCESS $\mathrm{AA}_{\mathrm{A}}$ and SUCCESS $_{\mathrm{AA}}{ }^{*}$ simply account for two varyingly strong senses of what it is for an agent to have an ability. There seems to be an important difference between an understanding of abilities according to which the agent's $\phi$-ing has to be appropriately tied to the intention to $\phi$ itself on the one hand, and an understanding of abilities according to which the agent's $\phi$-ing merely has to be tied to some intention, on the other.

In the former, but not in the latter case, the agent is able perform the act in question at will and is able to perform it upon request. Usually, I should think, this is the sense of ability we are interested in when we are thinking about abilities to perform actions. This sense is captured by the original success condition SUCCESS $_{\mathrm{AA}}$. Very importantly, it is a sense in which the agents in the examples lack the ability to $\phi$. Frieda cannot walk casually upon request; Fred cannot sing in tune upon request; Emma cannot make witty and hilarious remarks, Ela cannot do a handstand, and Peter cannot play the middle part of "Pour Élise" flawlessly upon request.

Cases of unintentional abilities - cases in which the performance of the action is properly linked, not to the intention to perform that very action, but some other intention - seem to be deficient in one very crucial respect, then. There is a somewhat accidental element to abilities of that kind. Frieda's walk tends to turn out to be casual, Fred's singing tends to turn out to be in tune, and Emma's remarks tend to turn out to be funny. Likewise, Emma's attempt to hit her feet against the wall tends to result in a handstand, and Peter's play of "Pour 
Élise" tends to involve a flawless performance of the middle part. But this particular feature of their respective actions is not something the agents bring about intentionally - it is not fully controlled by the agents. ${ }^{18}$

This suggests the following picture: whenever an agent has an agentive ability, there is some action which the agent can perform upon request - there is an action which is appropriately linked to the agent's intention to do that very thing. In the examples, the actions of that kind are walking, singing, giving talks, performing certain bodily movements, and playing "Pour Élise" start to finish. For those actions, the original success condition SUCCESS $_{\mathrm{AA}}$ holds.

In some cases, however, the ability we ascribe is not the ability to do that very thing, but a different thing: walking casually, singing in tune, making hilarious remarks, doing a handstand, and playing the middle part of "Pour Élise" flawlessly, for instance. Why do we do that? Because the thing the agent is able to do upon request is such that it usually turns out in a certain way: casually, in tune, and so forth. That is why the agent's walking casually, singing in tune, and making witty and hilarious remarks are themselves modally tied in the right way to the intention to do whatever the agent can do upon request. The original formulation of the success condition is still the primary one on this picture. But the more liberal formulation comes into play whenever there is something the agent can do, even though she cannot do it upon request or at will.

End of story? Not quite. One may object that $\mathrm{SUCCESS}_{\mathrm{AA}}{ }^{*}$ is in fact a bit too liberal. On my account, an agent has an ability to $\phi$, in the liberal sense, whenever there is some intention, no matter whether it is the intention to $\phi$ or not, to which the agent's $\phi$-ing is closely enough tied. But that does not seem right, does it? Suppose I have the disposition to twitch my left eye whenever I am nervous, and to feel nervous whenever I talk to Ben, which in turn I do pretty much whenever I intend to. It seems as though SUCCESS AA $^{\star}$ yields that I have the ability to twitch my left eye. There is some intention - the intention to talk to Ben - such that I twitch my left eye in a sufficient proportion of relevant possible situations in which I form that intention. And that is weird. It does not seem as though I have an ability to twitch my left eye. My eye twitching is just something that happens to me when I am nervous. I have no control over it whatsoever.

18 That there is a lack of control might be least obvious in Peter's case of playing the middle part of "Pour Élise". But what actually happens in that case, I take it, is that once Peter starts playing the piece, some automatism sets in, which carries him flawlessly through the whole piece. Peter does not, in that sense, fully control what is going on. He is being carried along a great deal. Of course, there is some control involved: the agent can stop playing the middle part. But there is not full control over what is happening and how. 
Again, we have to be careful here, though. Recall that we are dealing exclusively with agentive abilities. Agentive abilities are abilities to perform actions. And twitching my eye fails to be just that: it is not an action. Hence, there is indeed one restriction to SUCCESS ${ }_{\mathrm{AA}}{ }^{*}$, which I should once more add very explicitly: $\phi$-ing has to be an action. It must not be a mere behavior.

Are there still counterexamples to SUCCESS $_{\mathrm{AA}}{ }^{\star}$ ? I find it hard to think of one, but perhaps there are some. If you can think of one, let me put you on hold until the next chapter. For as we'll see there, SUCCESS ${ }_{\mathrm{AA}}$ * is not fully spelled out quite yet. What is missing, and what is actually quite crucial to the success view, is the requirement that there has to be success involved in the performance of $\phi$-ing. More specifically, SUCCESS AA $^{*}$ misses out on the fact that in addition to the agent's $\phi$-ing in a sufficient proportion of the relevant possible situations in which the agent has some intention, the agent's $\phi$-ing in response to that intention also has to count as a success. Really, then, SUCCESS $_{\mathrm{AA}}$ * needs to be replaced by the following, more subtle view:

SUCCESS $_{\text {AA_COMPLETE. }}$ An agent $\mathrm{S}$ has an agentive ability to $\phi$ if and only if (i) there is some intention $\psi$, such that $S$ 's in a sufficient proportion of similar situations in which she intends to $\psi$, where $\phi$ and $\psi$ need not specify the same action type, as long as (ii) $\phi$-ing in response to $\psi$ counts as a success.

Condition (ii) may not be fully accessible at this point, but things will fall into place in the next chapter. For now, let us just note that there is a more liberal notion of having the ability to $\phi$, which has to do with the fact that what the agent intends to do need not be precisely what she ends up doing. In the next section, I'll differentiate this insight further.

\subsection{Impairments by ignorance}

The cases in the last section seemed to indicate that agentive abilities do not require a proper link between the intention to $\phi$ and the agent's $\phi$-ing. That is because in cases of finkish abilities and unintentional abilities more generally that link is violated. Yet, the agent has the ability. I argued that unintentionally abilities are very interesting, but not actually problematic for the success view. What they show is that there are actually two senses of an agent being able to do something, which should be kept separate. The sense in which the agent has the ability in cases of unintentional abilities is weaker than the standard sense of ability, but a proper sense nevertheless. What I established in the last section is a distinction between two varyingly strong readings of the success con- 
dition, which provides the resources to distinguish systematically between those two senses.

In this section, we'll look at a further kind of unintentional agentive abilities: cases that involve what I will call impairments by ignorance. Here are some cases illustrating this phenomenon:

C MINOR. Klaus has the ability to grab a C minor chord. But he doesn't know that the chord he so effortlessly grabs and thinks of as "the cool chord" is a $\mathrm{C}$ minor. In fact, he thinks " $\mathrm{C}$ minor" is the name for the $\mathrm{D}$ minor chord. Thus, it is not the case that he grabs a $\mathrm{C}$ minor in a sufficient proportion of relevant possible situations in which he intends to grab a $\mathrm{C}$ minor.

CHATTING. Karl has the ability to chat casually with the president of the United States, but only in virtue of the fact that he fails to recognize him. Knowingly talking to the president would actually freak him out. Thus, it is not the case that he chats casually to the president in a sufficient proportion of relevant possible situations in which he intends to chat casually with the president.

BRESLAU. Ela has the ability to cycle from Warsaw to Breslau. Ela believes, however, that "Breslau" is the German word, not for the Polish city Wroclaw, but for the country of Belgium. Hence, it is not the case that Ela cycles to Breslau in a sufficient proportion of relevant possible situations in which she intends to do so. She would either end up in Belgium, or, even more likely, give up somewhere along the way.

Again, these cases seem to show that the link between intentions and performances that is postulated by the success view is not necessary. The agents in the examples have an ability to $\phi$, while it is not the case that their $\phi$-ing is properly linked to their intentions to $\phi$.

Against the background of the last section, one response to the examples is obvious. As in the last section, the agents clearly meet SUCCESS $_{\mathrm{AA}}{ }^{\star}$. There is some intention such that S $\phi$ 's in a sufficient proportion of situations in which she forms that intention ${ }^{19}$. Klaus grabs a $\mathrm{C}$ minor in a sufficient proportion of similar situations in which he intends to grab "the cool chord". Karl chats casually with the president in a sufficient proportion of similar situations in which he intends to chat with "that guy" (where "that guy" refers to the president). Ela cycles to Breslau in a sufficient proportion of similar situations in which she intends to cycle to Wroclaw.

What this shows is that all of the agents have the ability to $\phi$ in the liberal sense established in the last section: for all of them, there is some intention they can form, such that they $\phi$ in a sufficient proportion of similar situations in which they form that intention. What they fail to exhibit is the ability in the

19 And doing so counts as a success, but let's postpone this until the next chapter. 
stronger, original sense: the intention that is properly tied to their $\phi$-ing is not the intention to $\phi$.

Yet, there is more to say about cases of impairments by ignorance. To see that, note that there seems to be a relevant difference between the sense in which the agents we considered in the last section have the ability to do something and the sense in which the agents we are considering right now have an ability. In the last section, the cases we looked at were crucially characterized by the fact that there were certain parts or aspects of the agents' doings that are not fully controlled by the agents. Our agents were able to walk, sing, try to hit their feet against the wall, and to play "Pour Élise" in the strong sense, while not being in the same strong sense able to walk casually, sing in tune, do a handstand, or play the middle part of "Pour Élise". These aspects of parts of their doings were something they did not fully control. In that sense, we said, our agents are only weakly able to do the things in question.

In cases of impairment by ignorance, diminished control is not at issue at all. The agents control their actions fully when exercising them. There is no passive or automatized element to their doings whatsoever. In this respect, they seem to resemble agents who are able to perform an action in the strong sense. In terms of control, they resemble agents whose intention to $\phi$, and not just some other intention, is properly linked to their performances of $\phi$-ing.

Why is that? The answer has to do with the fact that in cases of impairments by ignorance, there is a much closer relation between the intention to which the agent's performances of $\phi$-ing are tied and the act of $\phi$-ing itself than in other cases of unintentional abilities. Cases of impairment by ignorance differ from other cases of unintentional abilities in one very crucial respect. The thing the agents intend to do is the act of $\phi$-ing, albeit under a different description. Grabbing "the cool chord" is grabbing C minor. Chatting casually to "that guy" is chatting casually to the president. Cycling to "Breslau" is cycling to Wroclaw.

The same is not true in the cases we looked at in the last section. It is not true that just walking is walking casually, that just singing is singing in tune, or just trying to kick one's feet through the wall is doing a handstand. It is this difference between the cases of impairments by ignorance and other unintentional abilities which accounts for the fact that ignorant agents, while resembling the agents from the last section in not exhibiting the proper tie between their intentions to $\phi$ and their performances of $\phi$-ing, have full control over their performances of $\phi$-ing.

This yields the following picture: in all cases of unintentional abilities, agents are able to $\phi$ only in the liberal sense established in the last section. They are able to $\phi$ only in the sense that there is some intention, the intention to $\psi$, such that the agents $\phi$ in a sufficient proportion of the relevant possible 
situations in which they form that intention. But while $\psi$ and $\phi$ are not necessarily closely related in unintentional abilities in general, they pick out one and the same action in the cases of ignorance. This accounts for the fact that there is no lack of control involved in the latter.

The basic insight we need in order to be able to understand how impairments by ignorance differ from the cases in the last section, then, is that "to intend to $\phi$ " can be read in two different ways: it can be given a de dicto reading or a de re reading (locus classicus: Quine 1956). In the de dicto reading, one intends to $\phi$ only if the content of one's intention is "to $\phi$ ". In the de re reading, in contrast, one also intends to $\phi$ if the content of one's intention is "to $\psi$ ", where $\psi$ ing is $\phi$-ing.

The objection from impairments by ignorance obviously depends on a de dicto interpretation of "intending to $\phi$ ". In the examples, it is not the case that the agent $\phi$ 's in a sufficient proportion of the relevant possible situations in which the agent intends, de dicto, to $\phi$. Klaus, for instance, grabs D minor whenever he intends, de dicto, to grab $\mathrm{C}$ minor. However, and this is the important point, in the de re sense of "intending to $\phi$ ", the agents' intentions are properly tied to their performances. Klaus grabs $\mathrm{C}$ minor in a sufficient proportion of the relevant possible situations in which he intends, de dicto, to grab the cool chord. But since grabbing the cool chord just is grabbing $\mathrm{C}$ minor, it is also the case that he grabs $\mathrm{C}$ minor in a sufficient proportion of the relevant possible situations in which he intends, de re, to grab $\mathrm{C}$ minor. Likewise in the other cases.

SUCCESS $_{\mathrm{AA}}$ can be read in two ways, then:

(1) An agent $S$ has the ability to $\phi$ if and only if $S \phi$ 's in a sufficient proportion of the relevant possible situations in which $\mathrm{S}$ intends, de dicto, to $\phi$.

(2) An agent $S$ has the ability to $\phi$ if and only if S $\phi$ 's in a sufficient proportion of the relevant possible situations in which S intends, de re, to $\phi$.

In cases of impairments by ignorance, (1) is violated. But (2) is not. And thus, there is a good sense in which the agents have the ability to $\phi$ in the strong sense spelled out by SUCCESS $_{\mathrm{AA}}$, and not just in the weak sense spelled out by SUCCESS $_{\mathrm{AA}}{ }^{\star}$, in those cases. Cases of impairments by ignorance are therefore unintentional only on the de dicto reading of $\operatorname{SUCCESS}_{\mathrm{AA}}$. 


\subsection{Upshot}

Let's wrap up our findings in this chapter. The objective of the chapter was to develop a comprehensive view of agentive abilities - abilities to perform actions. I suggested, somewhat provisionally, that having an agentive ability is a matter of modal success in the sense that the agent has to $\phi$ in a sufficient proportion of the relevant possible situations in which the agent intends to $\phi$. I called this "the success view of agentive abilities", or SUCCESS $_{\mathrm{AA}}$ for short.

SUCCESS $_{\mathrm{AA}}$ is a hybrid of the simple conditional analysis and possibilism, in the sense that SUCCESS ${ }_{\mathrm{AA}}$ combines both the idea that abilities are a matter of a modal tie between the agent's intentions and performances and the idea that abilities are always had in view of certain facts, where those facts impose restrictions of the realm of the possible situations.

After introducing the basic framework, I first $(\rightarrow 4.2)$ elaborated on the notion of an intention, as it figures in the success view, and provided a rationale for formulating the view in those terms. An intention, I said, is simply an action initiating propositional attitude in the sense that it is part of its causal role that it will typically initiate behavioral episodes corresponding to its content. The behavioral episodes which are caused by intentions (in the right way) ${ }^{20}$ are actions. Why does the success view feature intentions and not any other motivational state? Because only intentions are both action-initiating in the specified sense and not themselves actions. This is important, because only an action-initiating state secures that a failure to $\phi$ really counts against the ability and does not simply trace back to overriding other mental attitudes, and only a mental state that is not itself an action secures that SUCCESS $_{\mathrm{AA}}$ does not run into a regress.

The lion's share of the chapter $(\rightarrow 4.3-4.7)$ was devoted to presenting the merits of SUCCESS AA. As I argued at great length, SUCCESS $_{\mathrm{AA}}$ accounts for all of the adequacy conditions for a comprehensive view of (agentive) abilities and does not run into any of the problems that beset the simple conditional analysis and possibilism. Let me briefly walk you through those merits once more.

In section 4.3, I showed that the success view provides a comprehensive account of degrees and the corresponding kind of context sensitivity of ability statements. The degree of an ability to $\phi$, I argued, corresponds to the weighted proportion of the relevant intention situations in which the agent $\phi$ 's. Here, we

20 "In the right way" means: by non-deviant causal chains. How to think of non-deviance is a problem of action theory and falls outside the scope of this book. For an overview see Wilson \& Shpall (2012, section 2). 
added the first important supplement to the original statement of the success view. What matters, for an agent's ability to $\phi$ is that the agent $\phi$ 's in a sufficient weighted proportion of the relevant possible situations in which the agent intends to $\phi$.

In section 4.4, I showed that the success view does not run into problems with cases of impeded intentions. The success view entails what I called "the existential requirement": for SUCCESS AA $_{\text {to }}$ to met, there have to be relevant possible intention situations to begin with. As I argued, the existential requirement is not met in cases of impeded intentions. In such cases, there are neither relevant intention situations, nor are there any performance cases among the relevant intention situations. That is not to say that there is no good sense in which coma patients retain their ability to raise their arm whatsoever: depending on whether the coma is varied or held fixed across the possible situations, there will or will not be relevant intention situations and arm raising situations among those. This is exactly right: the problem of the impeded intention only arises when we are interested in what the agent can do in view of the impediment, such as the coma. When we are interested in what the agent can do, abstracting away from the coma, the agent retains lots of abilities. The success view can account smoothly for both senses.

In section 4.5, I argued that the success view provides a comprehensive account of general and specific abilities. When thinking about an agent's general abilities, we hold different sets of facts fixed than when we think about her specific abilities. In the case of general abilities, we are interested in what the agent can do in view of her stable, intrinsic properties. In the case of specific abilities, we are interested in what she can do in view of all kinds of temporary, extrinsic features that concern her current situation.

In the course of the section, I also systematized various ideas about the general/specific distinction that have been floating around in the literature. In section (a), I looked more closely at general abilities and argued against the idea that we only ever hold intrinsic features fixed in the case of general abilities. Instead, I argued, stability of features is what counts. I also argued that there is not one sense of "general ability", but many, which vary in accordance to just which set of stable, mostly intrinsic properties we hold fixed.

In section (b), I looked more closely at specific abilities and argued that there is not one sense of "specific ability", but many. I explicitly distinguished three that seem to me to be of particular systematic interest: (i) particular abilities, or abilities that are had in view of the totality of facts that obtain at some point in time, including the agent's motivational states; (ii) conative abilities, or abilities that are had in view of all facts of a situation except for the agent's motivational states; and (iii) opportunities, or abilities that are had in view of the 
features of the situation that are external to the agent. I also argued that there are many more good senses of "specific ability", which vary in accordance to just which set of features of the situation we hold fixed.

In section (c), I looked at the ways in which general and specific abilities depend on one another. Here, I argued that some specific abilities will be such that having such an ability requires having a corresponding general ability. I also argued that having a general ability generally requires that there be various possible situations in which the agent has a corresponding specific ability.

In section (d), I looked at degrees of specificity and argued that an ability A1 is more specific than an ability A2 if and only if the kinds of facts that are held fixed in the case of A1 are a proper subset of the kinds of facts that are held fixed in the case of A2. I also argued that this only yields a partial ordering of the specificity of abilities, which I take to be exactly right.

In section (e), finally, I looked at the ways in which hypothetical circumstances enter our thinking about abilities. I argued that the structure of ability statements has four placeholders for circumstances: "S can $\phi$ " is to be read as "In C1, $\mathrm{S}$ can, in view of $\mathrm{C}^{\star}$ and when $\mathrm{C} 3, \phi$-in-C2”, where hypothetical circumstances can enter via C1, C2, and C3, yielding different interpretations of the sentence.

In section 4.6, we turned to masks and saw that the success view explains the workings of masks very smoothly. Masks are not a problem for the success view, because the mask - the interfering factor in the actual situation - is usually varied across the relevant possible situations. That means that the very small proportion of situations in which the mask is present do not in any sense have priority over situations in which it is not present. And hence, the fact that the actual situation is a mask situation is not of particular interest. The actual situation does not have any special status among the realm of the relevant possible situations. Despite the mask, there may well be a sufficient proportion of performance cases among the relevant intention situations.

In section 4.7, I showed that the formal problem Kenny noted about possibilism does not arise for the success view. Quite to the contrary: the success view explains very smoothly why the laws that hold for the "can" of possibility do not hold for the "can" of ability.

In sections 4.8 and 4.9, finally, we turned to two closely related natural objections to the success view. In section 4.8, I discussed the objection that the success view runs into problems with what I called "unintentional agentive abilities" - agentive abilities which can only be exercised as long as the agent does not intend to exercise them. In section 4.9, the worry was refined by examining a particular kind of unintentional agentive abilities: abilities that can only be exercised as long as the agent does not intend to exercise them, because the agent is epistemically impaired in certain ways. 
In response to these objections, I introduced a somewhat weaker version of the success view, which accommodates such cases: on that view, an agent has an agentive ability to $\phi$ if and only if there is some intention to $\psi$, such that the agent $\phi$ 's in a sufficient proportion of the relevant possible situations in which the agent intends to $\psi$, where $\phi$ and $\psi$ need not specify the same action type, but where $\phi$-ing in response to intending to $\phi$ counts as a success. Depending on whether $\psi$ and $\phi$ pick out the same action type and depending on whether they pick out the same action type de dicto or de re, the view yields varying senses of "having an ability".

We are now in a position to formulate the fully comprehensive view of agents' agentive abilities we were after in this chapter:

AGENTIVE ABILITIES. An agent $\mathrm{S}$ has an agentive ability to $\phi$ if and only if $\mathrm{S} \phi$ 's in a sufficient proportion of the relevant possible situations in which $\mathrm{S}$ intends to $\psi$, where $\psi$ will typically be de dicto or de re identical to $\phi$ and in any case be such that $\phi$-ing in response to the intention to $\psi$ counts as a success.

As I said: the last bit of this condition - that $\phi$-ing in response to the intention to $\psi$ has to count as a success - will strike you as mysterious, because so far I have not talked about success as such. It's a cliff hanger. Everything will make sense in the next chapter, where we will proceed to extend the view to abilities of the non-agentive kind. 